\title{
A Farmácia e a Drogaria sob a Nova Ótica DA RDC N. 44/2009 DA ANVISA
}

\author{
PHARMACY AND DRUGSTORE IN A NEW \\ PERSPECTIVE OF THE RDC N. 44/2009 ANVISA
}

Lucio Sanches Esteves Pinto ${ }^{(*)}$

\section{RESUMO}

Este artigo tem o propósito de estudar a função exercida por estabelecimentos farmacêuticos no contexto da saúde pública, bem como analisar se essa atividade é de saúde ou comercial, sob a nova perspectiva de regulação da atividade aprovada pela ANVISA pela RDC 44/2009. Embora a atividade desenvolvida por esses estabelecimentos seja de inquestionável relevância para a saúde pública, isto não faz deles estabelecimentos de saúde, mas sim estabelecimentos comerciais de interesse da saúde. Nesse sentido, os objetivos almejados e os princípios defendidos pela ANVISA não serão alcançados com as mudanças impostas pelo novo regulamento de boas práticas farmacêuticas na medida em que os problemas existentes no comércio farmacêutico são consequências de uma política de saúde incompatível e insuficiente com as necessidades da população. Automedicação irresponsável, intoxicação e o consumo excessivo e irracional de medicamentos são problemas que serão solucionados apenas quando as autoridades agirem nas suas causas. A construção de novos hospitais em municípios onde não exista nenhum, a ampliação do atendimento médico-hospitalar, contratação de novos médicos e melhoria das suas condições de trabalho, investimento em educação sanitária, na formação e capacitação de farmacêuticos, integração da atenção farmacêutica ao Sistema Único de Saúde, intensificação da fiscalização, implementação de novas campanhas voltadas à defesa da saúde são exemplo de medidas que seguramente serão mais eficazes para a solução dos problemas existentes no comércio farmacêutico.

(*) Pós-graduando em Direito Sanitário pela Faculdade de Saúde Pública da Universidade de São Paulo (USP); Especialista em Direito Administrativo pela Universidade Mackenzie. Advogado. São Paulo/SP, Brasil. E-mail: <lucioasp1@gmail.com>.

Texto recebido em 16.09.10. Revisado em 28.09.10. Aprovado em 13.10.10. 


\title{
Palavras-chave
}

Drogaria; Estabelecimento de Saúde; Farmácia; Resolução ANVISA.

\begin{abstract}
ABSCTRACT
This article aimed to explore what role exerted by pharmacies and drugstores in the context of public health, and whether such establishments are health establishments or businesses under the new perspective of regulating the activity approved by the RDC 44/2009 ANVISA. Although the activity performed by these establishments has its unquestionable relevance to public health, this does not make them health facilities, but commercial establishments of health concern. Accordingly, the proposed objectives and principles espoused by ANVISA will not be reached with the changes required by new regulation of pharmaceutical practice because the problems in the pharmaceutical trade are consequences of a health policy inconsistent and insufficient to the needs of population. Irresponsible self-medication, intoxication and irrational drug use are problems that only will be solved if the authorities act on the causes of them. The construction of new hospitals in cities where there is not any, expansion of medical, hospital, hiring of new doctors and improvement of their working conditions, investment in health education, graduating and training of pharmacists, integration of pharmaceutical care to the Health System, intensified surveillance, implementation of new campaigns aimed at health protection are examples of measures that will surely be more effective to solve the existing problems in the pharmaceutical trade.
\end{abstract}

\section{Keywords}

Brazilian National Sanitary Surveillance Agency; Drugstore; Health Facility; Pharmacy.

\section{INTRODUÇÃO}

\section{O NOVO REGULAMENTO TÉCNICO DE BOAS PRÁTICAS FARMACÊUTICAS}

Em 18 de fevereiro de 2010 entrou em vigor a nova Resolução da Diretoria Colegiada da ANVISA n. 44/2009. Desde então, ela tem sido objeto 
de duras críticas e também de elogios dos diversos setores da sociedade em função de algumas inovações trazidas pelo texto normativo aprovado pela Agência.

Fruto de intensos debates desde a abertura da Consulta Pública n. 69/ 2007, a proposta era regulamentar as boas práticas farmacêuticas nos estabelecimentos farmacêuticos, transformando-os em estabelecimentos de saúde, retirando deles o caráter comercial da atividade. Segundo o Diretor-Presidente da Agência

(...) é possível encontrar nesses locais produtos como lâmpadas, pilhas, biscoitos, picolés, refrigerantes, revistas, calçados e até mesmo serviços, como pagamento de contas, revelação fotográfica e plastificação de documentos. Tudo isso traz prejuízo à correta orientação farmacêutica, o que, em última instância, contribui para o uso incorreto de medicamentos. $^{(1)}$

Para a Agência, as farmácias e drogarias não podem ser consideradas meros estabelecimentos comerciais, mas sim locais de promoção da saúde, integrados aos serviços públicos a ela relacionados. Porém, no modelo de negócio atualmente explorado no varejo farmacêutico, os estabelecimentos estão mais comprometidos com resultados financeiros positivos do que efetivamente com a saúde da população(2).

Embora as autoridades reconheçam a existência de leis e regulamentos que já tratam da matéria, também reconhecem a dificuldade de fiscalizar a atividade. A Lei Federal n. 5.991/73 proíbe aos estabelecimentos farmacêuticos a exploração indiscriminada do comércio de produtos estranhos à atividade. Porém, permite o comércio de alguns produtos classificados como "correlatos". É da definição legal que decorre a dificuldade no entendimento do que pode ou não ser enquadrado no conceito de produto correlato ${ }^{(3)}$.

Com efeito, a Constituição Federal classifica o direito à saúde como um direito fundamental a cargo do Estado. Todavia, é certo reconhecer a ineficiência dos serviços públicos de saúde. Nesse contexto, o Brasil enfrenta um problema crônico e complexo de se resolver. A farmácia é, em geral, o primeiro estabelecimento no qual a população busca auxílio em havendo sinais de agravo à saúde. E se não são estabelecimentos de saúde, mas sim

(1) Entrevista concedida pelo então presidente da ANVISA. Guia da farmácia Disponível em: <www.guiadafarmacia.com.br>. <http://guiadafarmacia.com.br/gestao-merchandising/201/debate-listareduzida-anvisa-propoe-que-produtos-considerados-conveniencia-deixem-167569-1.asp>. Acesso em: 24 maio 2010.

(2) ANVISA. Anvisa anuncia novas regras para farmácias e drogarias. 18 ago. 2009. Disponível em: <http://www.anvisa.gov.br/divulga/noticias/2009/180809_2.htm> Acesso em: 24 maio 2010.

(3) Art. 4º, inciso IV da Lei Federal n. 5991/73: Correlato - a substância, produto, aparelho ou acessório não enquadrado nos conceitos anteriores, cujo uso ou aplicação esteja ligado à defesa $e$ proteção da saúde individual ou coletiva, à higiene pessoal ou de ambientes, ou a fins diagnósticos e analíticos, os cosméticos e perfumes, e, ainda, os produtos dietéticos, óticos, de acústica médica, odontológicos e veterinários. 
"meramente comerciais" - segundo entendimento de uma significativa parcela das autoridades sanitárias - em tese, a população se expõe a um risco grande.

Por outro lado, há o interesse privado envolvido no comércio de medicamentos. Como toda e qualquer empresa, para sobreviver no mercado e cumprir seu papel socioeconômico, a drogaria e a farmácia precisam produzir lucros e resultados positivos para honrar seus compromissos trabalhistas, previdenciários, fiscais, comerciais, dentre outros, sem o que será condenada à falência.

Visando a melhoria dos resultados, as farmácias e drogarias passaram a explorar o comércio de diversos artigos que, em última análise, seriam estranhos ao comércio farmacêutico. Tornou-se comum encontrar produtos à venda que não se coadunam com o propósito destes estabelecimentos. É o caso de alimentos como picolés, bolachas e chicletes, produtos de limpeza e veterinários, roupas, calçados e materiais de cinema, fotografia e vídeo. Para a ANVISA, "o consumidor sai com a sacola de plástico lotada"(4).

Além do aspecto comercial com a venda desses produtos - tidos pelas autoridades como alheios e pelos empresários do ramo como correlatos as farmácias e drogarias estão sendo concebidas como se fossem verdadeiros "mercados", de modo que o cliente seja "induzido" ao consumo desnecessário daqueles medicamentos cuja venda não necessita de prescrição médica.

Com o novo Regulamento Técnico de Boas Práticas em Farmácias e Drogarias instituído pela RDC n. 44/2009 e respectivas Instruções Normativas, a ANVISA estabeleceu que "os medicamentos deverão permanecer atrás do balcão, para que os consumidores tenham acesso ao farmacêutico e possam esclarecer dúvidas quanto ao uso correto do produto". A ANVISA justifica que "com essa medida, pretende-se reduzir a automedicação [sic] e o uso abusivo de medicamentos"(5).

Uma das inovações trazidas pela resolução foi a regulamentação das vendas de medicamentos por telefone e/ou internet, a permissão da realização de alguns serviços como a medição da pressão arterial, glicemia capilar, atenção farmacêutica domiciliar e perfuração do lóbulo auricular. Antes da Resolução, a execução desses serviços nas farmácias e drogarias era proibida. Porém, não foi a permissão de execução de determinados "serviços farmacêuticos" que causou a enorme polêmica.

Os pontos mais polêmicos da resolução foram os textos das Instruções Normativas ns. 9/2009 e 10/2009. Esta trata da necessidade dos estabelecimentos adequarem suas instalações para que os Medicamentos Isentos de Prescrição

(4) ANVISA. Consumo e saúde, farmácia: local de promoção à saúde. Disponível em: <http:// www.anvisa.gov.br/ouvidoria/consumo_saude/11_090909.pdf>. Acesso em: 29 mai. 2010.

(5) Id. Ibid. 
(MIP) sejam colocados atrás dos balcões, de modo que os consumidores não mais tenham livre acesso a eles, sendo necessário o auxílio do funcionário do estabelecimento para pegá-los. Já aquela traz a normatização - ou "uniformização" - de quais produtos poderão ser comercializados nesses estabelecimentos.

Os Medicamentos Isentos de Prescrição (MIP) são aqueles que oferecem potencial de risco bem menor do que outros medicamentos (por exemplo, medicamentos para dor de cabeça, náuseas, gases, antigripais, etc.). Antes, eles ficavam dispostos diretamente nas gôndolas, ao alcance dos consumidores e sem a necessidade de intervenção de um funcionário do estabelecimento.

Para o Conselho Regional de Farmácia do Estado de São Paulo (CRF/ SP), um dos maiores defensores da RDC n. 44/2009, o "Medicamento isento de prescrição não é livre de orientação". ${ }^{(6)}$

A retirada dos medicamentos isentos de prescrição do alcance dos consumidores visa diminuir a chamada "automedicação" e uso irracional de medicamentos, além da prevenir as "reações adversas" e a intoxicação. Ao mesmo tempo, valoriza o profissional farmacêutico enquanto profissional da saúde. Já a proibição de comercialização de medicamentos estranhos ao comércio farmacêutico visa resgatar o papel das drogarias como estabelecimentos de saúde, comprometidos e integrados com ações de recuperação da saúde. Visa também evitar a contaminação do ambiente com outros produtos que possam prejudicar ou interferir no tratamento medicamentoso.

Com efeito, a nova RDC n. 44/2009 expõe uma questão de difícil solução para o Direito Sanitário: a dicotomia e o conflito existente entre a saúde, encarada como direito versus a saúde enquanto mercadoria ou bem de consumo. Ambos os interesses, comerciais (caracterizados pelo estabelecimento enquanto empresa) e sociais (refletidos no interesse que a saúde pública tem, inerente ao comércio de medicamentos) são expostos e se antagonizam. Nesse cenário, os estabelecimentos farmacêuticos estão no centro da discussão.

Qual é o verdadeiro papel que os estabelecimentos farmacêuticos devem exercer na sociedade? Com base na legislação sanitária atual, é possível que esses estabelecimentos cumpram o papel social reclamado pela Agência Nacional de Vigilância Sanitária?

Este trabalho tem o propósito de cotejar ambos os lados da balança: de um lado, os argumentos dos empresários do comércio farmacêutico, defen-

(6) Cf. CONSELHO REGIONAL DE FARMÁCIA DO ESTADO DE SÃO PAULO. Projeto Farmácia Estabelecimento de Saúde. Fascículo II -Medicamentos isentos de prescrição, São Paulo, 2009. Disponível em <http://www.crfsp.org.br/joomla/index.php?option=com_docman\&task=doc_download\&gid= 150\&ltemid=108>. Acesso em: 26 mai. 2010. 
sores da tese segundo a qual a drogaria e a farmácia são estabelecimentos comerciais e, na outra ponta, a ANVISA e os Conselhos Profissionais de Farmácia, defensores do argumento segundo o qual esses são estabelecimentos de saúde.

\section{A DROGARIA COMO ESTABELECIMENTO DE SAÚDE}

A ANVISA defende o argumento de que a drogaria não pode ser encarada como simples comércio. Os produtos comercializados nesses estabelecimentos influenciam diretamente na saúde da população e os medicamentos não podem ser tratados como simples mercadorias, tal como aquelas que o consumidor simplesmente apanha e paga no caixa como se estivesse em um supermercado.

Justificando a existência do novo marco regulatório, a ANVISA diz que as metas buscadas são: (i) alinhar os estabelecimentos na perspectiva da assistência e da atenção farmacêutica em busca da promoção do uso racional de medicamentos; (ii) eliminar distorções no mercado com relação à diversidade de produtos e serviços estranhos ao comércio farmacêutico; (iii) contribuir para a melhoria no atendimento à população por meio de maior comodidade e qualidade na perspectiva da saúde e não apenas do comércio de produtos diversificados. Assim, esses estabelecimentos devem prover (1) a informação e educação em saúde; (2) a prevenção e redução dos problemas relacionados a medicamentos e a questões relacionadas à saúde; (3) atenção farmacêutica; (4) atendimento focado na saúde do usuário e não somente no lucro(7). $^{(7)}$

A transformação desse comércio em estabelecimento de saúde é defendida por Romano-Lieber ${ }^{(8)}$. Invoca ele a proposta da OMS:

a missão da prática farmacêutica é prover medicamentos e outros produtos e serviços e auxiliar as pessoas e a sociedade a utilizá-los da melhor forma possível. Posteriormente, em 2006, a mesma OMS publicou um manual como referência para a reorientação da educação e da prática farmacêutica e a incorporação da atenção farmacêutica nesta prática. ${ }^{(9)}$

(7) SENADO. Audiência Pública da Comissão de Assuntos Sociais do Senado de 06 de maio de 2009. Boas práticas farmacêuticas em farmácias e drogarias. Disponível em: <HTTP://senado.gov.br/ web/comissoes/cas/ap/ano-de-2009/ap20090506_apresenta\%C3\%A7\%C3\%A3oANVISA.pdf>. Acesso em: 29 mai. 2010.

(8) ROMANO-LIEBER, Nicolina Silva; CUNHA, Marcelo Ferreira Carlos; RIBEIRO, Eliane. A farmácia como estabelecimento de saúde. Revista de Direito Sanitário, São Paulo, v. 9, n. 3, p. 188-199, 2008.

(9) Cf. World health organization. International pharmaceutical federation. Developing pharmacy practice: a focus on patient care, handbook 2006. Netherlands: World Health Organization/ International Pharmaceutical Federation. 2006. 97 p. Disponível em <http://www.fip.org/files/fip/ publications/DevelopingPharmacyPractice/DevelopingPharmacyPracticeEN.pdf>. Acesso em: 26 jun. 2010. 
Prossegue, invocando em favor dessa tese que se alinha a essa perspectiva, a Política de Medicamentos, a Política Nacional de Assistência Farmacêutica e a 1aㅡ Conferência Nacional de Vigilância Sanitária (2001), a $1^{\text {a }}$ Conferência Nacional sobre Medicamentos e Assistência Farmacêutica (2003). Todos esses eventos convergem

para a perspectiva de um novo modelo de farmácia que defina as suas funções no âmbito da recuperação, proteção e promoção da saúde. (...) A 1a Conferência Nacional sobre Medicamentos e Assistência Farmacêutica vai além, com uma proposta de "transformar o conceito de estabelecimentos farmacêuticos privados em estabelecimentos de serviços de saúde, integrados ao SUS de forma complementar, conforme legislação vigente".(10)

Nesse sentido, esses estabelecimentos desempenhariam papel importantíssimo no contexto da Saúde Pública e, em consequência, a transformação dos mesmos em "meros distribuidores" os descaracterizariam como estabelecimentos de saúde.

Segundo Gustavo Henrique Trindade da Silva, servidor da ANVISA e defensor das mudanças propostas pela RDC n. 44/2009, "tratar farmácia e drogaria como simples comércio tem sido um grande equívoco e tem contribuído para adoção de práticas comerciais abusivas, ou inadequadas, para a garantia de acesso seguro e qualificado da população a produtos ligados à saúde"(11).

\section{Medicamentos isentos de prescrição atrás do balcão}

A quantidade de produtos expostos aos consumidores, o forte e ostensivo apelo comercial das propagandas para o consumo de medicamentos, o livre acesso a medicamentos potencialmente causadores de intoxicações e de uso inadequado ou irracional, de fato, são argumentos contundentes. De acordo com o SINITOX (Sistema Nacional de Informações TóxicoFarmacológicas), o medicamento é maior agente causador de intoxicação humana(12).

(10) WORLD HEALTH ORGANIZATION. International pharmaceutical federation. Developing, cit. (11) SILVA, Gustavo Henrique Trindade da; OLIVEIRA, Neilton Araújo de. Farmácia e drogaria: simples comércio ou estabelecimento de saúde? Biblioteca Virtual em Saúde. Blog Direito Sanitário: Saúde e Cidadania, 05 Mar. 2010. Disponível em <http://blogs.bvsalud.org/ds/2010/03/05/farmaciae-drogaria-simples-comercio-ou-estabelecimento-de-saude/>. Acesso em: 24 maio 2010.

(12) BRASIL. Ministério da Saúde. Fundação Oswaldo Cruz. Sistema Nacional de Informações Tóxico-Farmacológicas - SINITOX. Brasília, DF. Disponível em <http://www.fiocruz.br/sinitox_novo/ cgi/cgilua.exe/sys/start.htm?tpl=home> . Disponível em: <http://senado.gov.br/web/comissoes/cas/ ap/ano-de-2009/ap20090506_apresenta\%C3\%A7\%C3\%A3oANVISA.pdf>. Acesso em: 24 maio 2010. 
Assim, ainda que sejam medicamentos isentos de prescrição médica (MIP), segundo entendimento da ANVISA, eles podem expor os usuários a riscos se forem consumidos sem a necessária orientação e acompanhamento. Retirando do alcance dos consumidores, espera-se a mudança da cultura popular da automedicação e que eles sejam dispensados e consumidos com orientação do farmacêutico.

Um dos defensores mais vigorosos da RDC n. 44/2009 é o Conselho Regional de Farmácia do Estado de São Paulo. Antes mesmo da nova Resolução ser aprovada, o CRF/SP já tinha proposto um projeto denominado "Farmácia Estabelecimento de Saúde". O projeto defende que a farmácia é um estabelecimento sanitário irradiador dos conhecimentos e cuidados à saúde e, sobretudo, a promoção do uso racional de medicamentos. Daí segue que um estabelecimento farmacêutico com um apelo altamente comercial, sem comprometimento com outras questões, mas apenas com o lucro, induzem a população ao consumo desnecessário de medicamentos e, em muitos casos, o consumo de produtos não relacionados com a saúde, talvez até prejudiciais, como por exemplo, bebidas alcoólicas e cigarros ${ }^{(13)}$.

O Conselho acredita que a farmácia poderia auxiliar o Estado na implementação de diversas políticas de orientação, prevenção e recuperação da saúde, para o que o farmacêutico responsável técnico desempenharia papel fundamental:

Para que as farmácias e drogarias recuperem seu verdadeiro papel social é imprescindível uma reorientação transformadora pela qual se tornem reais estabelecimentos de saúde. Para isso é necessária a assistência de profissionais tecnicamente habilitados e capacitados que assegurem e fortaleçam a assistência farmacêutica, sobretudo a dispensação e o uso correto, seguro e racional de medicamentos. ${ }^{(14)}$

A indução ao consumo desnecessário e irracional de medicamentos - a conhecida prática da "empurroterapia" - , a propaganda enganosa e a comercialização de todo tipo de produto nos estabelecimentos seriam distorções existentes nesse ramo que contribuiriam ainda mais para o agravamento da saúde da população que encontra nesses estabelecimentos uma "alternativa para tratamento de sua saúde".

As reuniões realizadas pela OMS em Nova Delhi (1988), Tóquio (1993), Vancouver (1997) e Haia (1998), além do Fórum Farmacêutico das Américas, repensaram a atuação do farmacêutico no Sistema de

(13) ESTABELECIMENTO de saúde. Disponível em: <http://www.crfsp.org.br/joomla/Diversos/ PDFFciaEstSaude.pdf>.

(14) Cf. CONSELHO REGIONAL DE FARMÁCIA DO ESTADO DE SÃO PAULO. Projeto Farmácia Estabelecimento de Saúde. Fascículo I, São Paulo, 2009. Disponível em <http://www.crfsp.org.br/ joomla/index.php?option=com_docman\&task=doc_download\&gid=149\&ltemid=108>. Acesso em: 26 mai. 2010. 
Atenção à Saúde, pois até então este profissional era responsável apenas pelo abastecimento de medicamentos, não exercendo sua principal função, a saber, a atuação como co-responsável na terapia do paciente e na promoção do uso racional dos medicamentos.

Na perspectiva desta nova prática profissional, o farmacêutico passa também a ser o responsável pelo processo de utilização dos medicamentos, bem como pela obtenção de resultados terapêuticos. Seu enfoque principal é o usuário, e não mais apenas o produto. Dessa forma, o farmacêutico passa a participar ativamente na prevenção das enfermidades e na promoção da saúde, juntamente com outros membros da equipe multidisciplinar. A consolidação do papel do farmacêutico como um profissional a serviço da sociedade contribui fortemente para o resgate, junto à população, da imagem da farmácia como estabelecimento de saúde.(15)

Para o CRF/SP, só haverá sucesso com tratamento medicamentoso por meio dos "MIP's" se o farmacêutico estiver à frente da dispensação, indicando qual o melhor medicamento a ser utilizado para a queixa do paciente, alertando-o sobre o uso e o abuso daquele produto:

Além disso, evidencia-se o crescente estabelecimento de uma cultura popular de que os MIP são produtos sem risco à saúde. Esses fatores levam ao aumento da utilização irracional dessa categoria de medicamentos. É nesse cenário que o papel do farmacêutico, enquanto profissional de saúde responsável pela orientação da utilização correta dos medicamentos, faz-se fundamental. Os MIP compõem uma categoria de medicamentos na qual a intervenção farmacêutica é o principal fator para o sucesso e a segurança da terapia, e por isso esse tema integra-se ao projeto Farmácia Estabelecimento de Saúde.(16)

A proposta do CRF/SP é fazer com que o farmacêutico aplique um questionário no paciente e, identificando possíveis e eventuais problemas no uso dos medicamentos isentos de prescrição e "recomende"[!] ${ }^{(17)}$, de acordo com os resultados da entrevista, qual o melhor medicamento a ser utilizado, praticamente atuando como médico.

Manifestando-se a respeito da nova normatização proposta pela ANVISA, a Presidente do CRF/SP Dra. Raquel Cristina Delfini Rizzi disse que:

hoje a farmácia é um estabelecimento totalmente comercial, onde você tem disponível aos olhos todos os medicamentos isentos de prescrição, num

(15) Cf. CONSELHO REGIONAL DE FARMÁCIA DO ESTADO DE SÃO PAULO. Projeto Farmácia Estabelecimento de Saúde. Fascículo II - Medicamentos isentos de prescrição, cit.

(16) Id. Ibid.

(17) "Recomendar" é o verbo utilizado pelo Manual. 
"self-service". Alguns acham que acabar com isso é autoritarismo. Mas o consumidor não deixará de comprar o que quer. Só vai ter a orientação certa. Uma coisa é comprar sapato. Outra coisa é medicamento. ${ }^{(18)}$

Em que pese a proibição da exposição dos MIP's ao alcance do consumidor, curiosamente o novo regulamento técnico de boas práticas farmacêuticas permitiu algumas exceções. A Instrução Normativa n. 10/2009 determinou que os medicamentos fitoterápicos, medicamentos administrados por via dermatológica e, finalmente, os medicamentos sujeitos à notificação simplificada, conforme legislação específica, podem continuar ao alcance dos consumidores ${ }^{(19)(20)}$.

O tema do uso racional de medicamentos foi objeto de um painel realizado na ANVISA no último dia 11 de fevereiro de 2010. Nesse painel, muitos participantes debateram o assunto, em especial a questão do consumo de medicamentos isentos de prescrição e os riscos relacionados com o consumo inadvertido e exagerado de determinados fármacos. $\mathrm{Na}$ oportunidade, a Prof. - Dra. Bagnólia Araujo da Silva destacou os riscos e possíveis efeitos tóxicos decorrentes do consumo de diversos fármacos, bem como possíveis efeitos indesejados ou reações adversas que podem ser verificados pelo consumo desses medicamentos. O painel procurou demonstrar, de maneira bastante técnica, quais os problemas decorrentes

(18) Disponível no site da ASSOCIAÇÃO MÉDICA DO PARANÁ. É drogaria ou supermercado? Disponível em: <http://amp.org.br/?p=2354>. Acesso em: 28 mai. 2010.

(19) Medicamentos fitoterápicos são medicamentos obtidos a partir de plantas medicinais. Eles são obtidos empregando-se exclusivamente derivados de droga vegetal (extrato, tintura, óleo, cera, exsudato, suco e outros). Não é objeto de registro como medicamento fitoterápico, planta medicinal ou suas partes, após processos de coleta, estabilização e secagem, podendo ser íntegra, rasurada, triturada ou pulverizada. Os fitoterápicos, assim como todos os medicamentos, devem oferecer garantia de qualidade, ter efeitos terapêuticos comprovados, composição padronizada e segurança de uso para a população. A eficácia e a segurança devem ser validadas por meio levantamentos etnofarmacológicos, documentações tecnocientíficas em bibliografia e/ou publicações indexadas e/ou estudos farmacológicos e toxicológicos pré-clínicos e clínicos. A qualidade deve ser alcançada mediante o controle das matérias-primas, do produto acabado, materiais de embalagem, formulação farmacêutica e estudos de estabilidade. ANVISA. Medicamentos (Medicamentos Fitoterápicos). Disponível em: <http://www.anvisa.gov.br/ medicamentos/fitoterapicos/definicao.htm>. Acesso em: 29 maio 2010. Já os medicamentos de notificação simplificada são aqueles produtos farmacêuticos, tecnicamente obtidos ou elaborados, com finalidade profilática, curativa ou paliativa na qual existe baixo risco de que seu uso ou exposição possa causar consequências e ou agravos à saúde quando observadas todas as características de uso e de qualidade descritas minuciosamente no Anexo I da RDC n. 199 de 26 de outubro de 2006 (ANVISA. Disponível em: <http://bvsms.saude.gov.br/bvs/saudelegis/anvisa/ 2006/res0199_26_10_2006_rep.html>. Acesso em: 29 mai. 2010.

(20) Este trabalho não teve o propósito de estudar sob o prisma técnico, qual foi o motivo que levou a Agência a diferenciar, dentre os Medicamentos Isentos de Prescrição, quais poderiam ficar ao alcance do consumidor e quais deveriam ser retirados das gôndolas. No entanto, esse foi um fato que chamou a atenção da pesquisa, pois esses medicamentos - todos eles, indistintamente embora estejam enquadrados na classificação de medicamentos isentos de prescrição, ainda podem ficar ao alcance dos consumidores. 
do consumo abusivo destes fármacos, reações adversas, intoxicações e interações medicamentosas, contraindicações e eventuais grupos de risco(21).

Evidente que todos os fármacos produzem efeitos no organismo, é da sua própria natureza. Aliás, essa propriedade é típica de qualquer medicamento, isento ou não de prescrição. Por isso, parece-nos pouco produtivo discutir se o consumo de medicamentos isentos de prescrição pode causar reações não desejadas. O que é preciso analisar, com o devido respeito e acatamento, é como se dá a automedicação e os motivos pelos quais esses medicamentos estão sendo consumidos sem orientação.

Interessante trabalho publicado na Revista de Saúde Pública relata alguns dados do perfil da automedicação no Brasil. O estudo concluiu que a automedicação "é um procedimento caracterizado fundamentalmente pela iniciativa de um doente, ou de seu responsável, em obter ou produzir e utilizar um produto que acredita lhe trará benefícios no tratamento de doenças ou alívio de sintomas"(22). Logo no início do trabalho, os autores afirmam que a automedicação:

é prática comum, vivenciada por civilizações de todos os tempos, com características peculiares a cada época e a cada região. Considerando a automedicação como uma necessidade, e inclusive de função complementar aos sistemas de saúde, particularmente em países pobres, a Organização Mundial de Saúde (OMS) publicou diretrizes para a avaliação dos medicamentos que poderiam ser empregados em automedicação. Segundo esse informe, tais medicamentos devem ser eficazes, confiáveis, seguros e de emprego fácil e cômodo.(...)

A automedicação inadequada, tal como a prescrição errônea, pode ter como consequência efeitos indesejáveis, enfermidades iatrogênicas e mascaramento de doenças evolutivas, representando, portanto, problema a ser prevenido. É evidente que o risco dessa prática está correlacionado com o grau de instrução e informação dos usuários sobre medicamentos, bem como a acessibilidade dos mesmos ao sistema de saúde. Certamente a qualidade da oferta de medicamentos e a eficiência do trabalho das várias instâncias que controlam este mercado também exercem papel de grande relevância nos riscos implícitos na automedicação. ${ }^{(23)}$

(21) Disponível no site da ANVISA. Uso racional de medicamentos é assunto de painel em Brasília. 11 fev. 2010. Disponível em: <http://portal.anvisa.gov.br/wps/portal/anvisa/busca/!ut/p/c5/ 04_SB8K8xLLM9MSSzPy8xBz9CP0os3hnd0cPE3MfAwMDMydnA093Uz8z00B_AwN_Q_1wkA48 Kowg8gY4gKOBvp9Hfm6qfkF2dpqjo6liAJYj_8M!/dl3/d3/L2dJQSEvUUt3QS9ZQnZ3LzZfS1FISUcw MDI5T1Q4RDBJNFRSSDILQ09GMTE!/?WCM_GLOBAL_CONTEXT=/wps/wcm/connect/Anvisa/Anvisa/ Sala+de+Imprensa/Noticias/Uso+racional+de+medicamentos+e+assunto+de+painel+em+Brasilia> . Acesso em: 29 mai. 2010.

(22) PAULO, L.G.; ZANINE A.C. Automedicação no Brasil. Rev. Ass .Med. Bras., v. 34, p. 69-75, 1988. (23) ARRAIS, Paulo Sérgio D.; COELHO, Helena Lutéscia L.; BATISTA, Maria do Carmo D. S.; CARVALHO, Marisa L.; RIGHI, Roberto E.; ARNAU, Josep Maria. Perfil da automedicação no Brasil. Revista de Saúde Pública, São Paulo, v. 31, n. 1, 71-77, 1997. 
Importante destacar que o trabalho acima mencionado levou em consideração não apenas medicamentos isentos de prescrição, mas sim todos os tipos de medicamentos - inclusive os de uso controlado.

Destarte, a retirada dos medicamentos isentos de prescrição das gôndolas teve o propósito de reduzir o consumo inadequado desses fármacos, obrigando o consumidor a solicitá-lo no balcão ao farmacêutico ou a outro funcionário do estabelecimento para garantia da orientação farmacêutica adequada.

\section{NORMATIZAÇÃO DO COMÉRCIO DE PRODUTOS CORRELATOS}

Em outra parte, a Instrução Normativa n. 09/2009 aprovou a "relação de produtos permitidos para dispensação e comercialização em farmácias e drogarias". A lista com os produtos permitidos incluiu o comércio de produtos para bebês (mamadeiras, chupetas, bicos e protetores de mamilo) e produtos de higiene e toucador, como lixas e cortadores de unha, escovas, toucas, pentes entre outros.

Além disso, a norma descreveu com razoável nível de detalhes quais os alimentos que poderão ser comercializados nesses estabelecimentos. São eles: alimentos para dietas com restrição de nutrientes (adoçantes dietéticos, restrição de carboidratos, sacarose, frutose ou glicose, etc.); alimentos para ingestão controlada de nutrientes (alimentos para controle de peso, praticantes de atividades físicas, repositores hidroeletrolíticos, suplementos vitamínicos, etc.) e alimentos para grupos populacionais específicos (bebês, gestantes, idosos, diabéticos, etc.).

Com isso, a Agência tentou uniformizar a exposição de produtos nas farmácias e drogarias, bem como descaracterizar tais estabelecimentos do modelo atual de "loja de conveniência" ou de "mercado", resgatando por consequência seu papel como estabelecimentos de saúde.

Com o novo marco regulatório, apenas os alimentos com alegação de propriedades terapêutico-funcionais devidamente registrados no Ministério da Saúde podem ser comercializados.

Curiosamente, a exemplo da exceção feita com relação a alguns Medicamentos Isentos de Prescrição (de notificação simplificada, os fitoterápicos e os de uso dermatológico), a Agência permitiu a comercialização de outros alimentos que, antes do novo marco regulatório, eram sempre objeto de questionamento por parte das autoridades como sendo produtos alheios ao ramo farmacêutico. É o caso dos chás, mel, própolis e geleia real.

Não há necessidade de registro desses produtos no Ministério da Saúde, mas, ainda assim, eles podem ser comercializados. Por outro lado, foi vedado o comércio de água, produto para cuja comercialização é exigido o registro no MS. 
Não são claras as motivações da ANVISA para tais diferenciações. O modo de exposição desses produtos potencialmente estimularia os consumidores a adquirir mercadorias desnecessárias, contribuindo para a contaminação dos fármacos com outros produtos que poderiam comprometer sua eficácia.

Com efeito, o conceito legal de produto correlato(24) permite uma amplitude não desejada pelas autoridades em relação ao comércio desses produtos nas drogarias e farmácias. Assim, bastaria encontrar algum "uso ou aplicação na saúde" para que esses produtos fossem comercializados.

Há, em algumas drogarias e farmácias, o comércio de determinados alimentos e bebidas. Porém, muitas autoridades entendem que as bebidas comercializadas (chás, sucos, refrigerantes, água de coco, entre outros) exceto aquelas com alegações de propriedades ou funcionalidades (isotônicos e repositores hidrolíticos por exemplo) — não têm nenhuma aplicação ou uso relacionado com a saúde.

Há também quem defenda a permissão do comércio de sorvetes e picolés. Para os comerciantes, esses produtos são recomendados por dentistas aos pacientes que fizeram extração de dentes - sobretudo os dentes adultos (sisos). A justificativa seria que a baixa temperatura proporcionada por esses alimentos ajudaria no tratamento e alívio da dor, minimizando o inchaço do rosto. Tudo isso sem contar com os produtos dietéticos, ou de baixa caloria. Considerando que o conceito de produto correlato da norma legal contém a expressão "produtos dietéticos", qualquer tipo de suco light vira um produto dietético. Vale esclarecer que os produtos dietéticos são aqueles elaborados sem adição de açúcar (para diabéticos), enquanto que o produto light é aquele com redução de gorduras, apenas, ou seja, é um alimento menos calórico.

Levando esses argumentos - e muitos outros - a certos "extremos", há de se reconhecer um certo abuso por parte dos empresários do ramo. Contudo, o texto da Lei n. 5991/73 dá margem a interpretações diversas, sobretudo após a reforma ocorrida em 1995 pela Lei Ordinária n. 9.069 que permitiu a comercialização de diversos artigos de "primeira necessidade" típicos de loja de conveniência e/ou drugstore(25).

Contudo, parece-nos que a ANVISA equivocou-se ao propor essas mudanças no varejo farmacêutico, em que pese a validade e relevância pública dos argumentos. A Agência tentou atingir um objetivo com as justificativas certas, mas com ações e políticas erradas. É, pois, o que passaremos a analisar.

(24) Vide nota 3 acima.

(25) A Lei Federal n. 9.069/1995 acrescentou no art. 4ํ da Lei o inciso XX que traz o conceito de loja de conveniência e drugstore: "estabelecimento que, mediante auto-serviço ou não, comercializa diversas mercadorias, com ênfase para aquelas de primeira necessidade, dentre as quais alimentos em geral, produtos de higiene e limpeza e apetrechos domésticos, podendo funcionar em qualquer período do dia e da noite, inclusive nos domingos e feriados." 


\section{A DROGARIA É UM ESTABELECIMENTO COMERCIAL}

Como visto acima, a ANVISA argumenta que as farmácias e drogarias são estabelecimentos de saúde. Desde logo, necessário reconhecer que esses estabelecimentos comercializam produtos de saúde, atividade cujo interesse público é inegável. Porém, a classificação deles como estabelecimentos de saúde é um grande equívoco.

Não se pode atribuir às farmácias e drogarias a grave missão de resolver problemas da saúde pública ou, pior ainda, imputar a elas a exclusiva responsabilidade pelo problema do consumo irracional de medicamentos, da intoxicação e da automedicação em decorrência da "postura comercial" com a qual esses estabelecimentos buscam o lucro.

Se de um lado há interesse público na proteção da saúde, há também relevante interesse público na expansão e fortalecimento da economia nacional, da geração de empregos, da função social das empresas, da arrecadação tributária, todos esses interesses de destaque constitucional.

Antes de atribuir a responsabilidade do problema às farmácias e drogarias, é preciso analisar quais os motivos que conduzem os brasileiros à automedicação e consumir medicamentos em demasia. É na ineficiência das políticas públicas de defesa da saúde, é na falta de recursos, na dificuldade de acesso aos médicos e nas suas péssimas condições de trabalho, nas estruturas físicas dos hospitais e centros de saúde, pronto-socorros e ambulatórios, na falta de profissionais farmacêuticos e no fraco ensino superior de farmácia que reside o problema.

Contudo, isso não significa dizer que o comércio de medicamentos pela rede privada não faça parte da solução do problema. Muito pelo contrário.

Em um sistema de saúde devidamente estruturado e capaz de atender todas as necessidades da população, as drogarias e farmácias poderiam desempenhar um papel complementar aos serviços de saúde, sobretudo na questão da atenção farmacêutica como um serviço de apoio na recuperação da saúde dos pacientes.

Mas o novo regulamento técnico de boas práticas farmacêuticas aprovadas pela ANVISA demonstra que as autoridades não estão atentas às reais necessidades dos brasileiros, mas sim atentas apenas às questões corporativas e totalmente ineficientes para solução da questão que envolve o comércio e o consumo de medicamentos no Brasil.

Esses estabelecimentos têm sim parcela de responsabilidade na questão e devem ser parte de um conjunto de ações e políticas voltadas à defesa da saúde - mas na exata medida das suas responsabilidade e possibilidades, observando-se acima de tudo o que determina a lei.

Não há dúvidas: as drogarias e farmácias são estabelecimentos fundamentalmente comerciais. E sendo comerciais, para que existam e 
permaneçam no mercado - atuando no seu papel de fornecer medicamentos a um preço competitivo, expandindo e aprimorando seus negócios - não há outra coisa a se fazer se não obter resultado financeiro positivo. Sem lucro, o estabelecimento fecha.

De outro lado, como dissemos, é inerente ao interesse público a regulação da atividade econômica desenvolvida pelas drogarias e farmácias. Exatamente por isso que a essa atividade econômica deve-se submeter à uma infinidade de exigências, tanto físicas quanto documentais. Esses estabelecimentos precisam da renovação anual do seu licenciamento, o que obriga as autoridades a realizarem inspeções sanitárias periódicas para conferir e exigir do estabelecimento o cumprimento de várias exigências, tais como a manutenção do ambiente em boas condições higiênico-sanitárias, a contratação de farmacêutico responsável técnico presente durante todo o horário de funcionamento, dentre outras.

Nesse sentido, será que a proposta de regulamentação das boas práticas farmacêuticas aprovada pela ANVISA se coaduna com esse propósito? Será que a ANVISA conseguirá atingir os objetivos almejados com a RDC n. 44/2009? A resposta à indagação infelizmente é negativa, senão vejamos.

\section{DA AUTOMEDICAÇÃO, DO CONSUMO IRRACIONAL E DA INTOXICAÇÃO POR MEDICAMENTOS}

A ANVISA justifica a retirada dos MIP's do alcance dos consumidores pelo fato de que, pela forma como eles são expostos, o consumidor é "induzido" a comprar sem necessidade, colaborando para piorar as estatísticas de intoxicação, do uso irracional de medicamentos e da automedicação. Mas será que essa medida contribuirá para reduzir os números do consumo irracional de medicamentos?

Um dos maiores opositores da medida é o Presidente da Associação Brasileira de Redes de Farmácias e Drogarias (ABRAFARMA). Em diversas manifestações, o executivo questiona a postura da Agência e coloca em dúvida se a regulamentação da atividade nesses moldes contribuirá ou atrapalhará a população:

O salário cai na sua conta e você pensa com o quê vai gastar seu dinheiro. Comprar roupas em um Shopping Center? Renovar o estoque de calçados? Fazer uma viagem? Ou passar na farmácia da esquina e levar alguns medicamentos para casa? (...) a nova Resolução da ANVISA (RDC 44/09) acabou colocando os remédios na categoria de bens de consumo e as drogarias na de centro de compras. A medida, além de restringir o acesso aos medicamentos isentos de prescrição médica, proíbe a venda de alguns produtos na drogaria. A ANVISA 
alega que, na compra de um sorvete, por exemplo, o consumidor seria influenciado a levar alguns remédios. O raciocínio oficial desmente toda a Teoria Econômica que vimos na escola. Medicamento é bem com demanda inelástica.

A medida da ANVISA, que defende transformar a farmácia em "estabelecimento de saúde", tem caráter ideológico e desconectado da realidade mundial. Vai na contramão de mercados desenvolvidos como EUA, França, Inglaterra, Itália e Suíça, onde a farmácia vem evoluindo para incluir, nos últimos anos, conveniência com uma série de facilidades para o consumidor.

(...) Esconder o remédio atrás do balcão, para evitar que as pessoas os tomem em demasia ou desnecessariamente, é uma nova forma de censurar os cidadãos, como se eles não soubessem comprar. Achar que o funcionário da farmácia vai orientar e impor limites ao consumidor não garante que os hipocondríacos continuem adquirindo remédios. Basta ir a várias farmácias e ninguém perceberá. E, principalmente, não evitará os excessos. ${ }^{(26)}$

O jornal O Estado de São Paulo de 20 de fevereiro de 2010 publicou duras críticas à medida:

(...) As novas medidas, que determinam que os estabelecimentos farmacêuticos comercializem somente produtos e serviços de saúde, entraram em vigor esta semana e sua imposição foi justificada como "garantia do cidadão à orientação farmacêutica".

Segundo a ANVISA, a farmácia é um estabelecimento diferenciado e seu "ambiente" não pode ser banalizado por produtos que não têm relação com sua atividade-fim nem por "armadilhas" que levem os clientes a adquirir medicamentos que envolvem riscos. Para a Agência, muitas farmácias e drogarias estão organizadas como supermercados. Ao colocar os mais variados tipos de remédios em gôndolas, de analgésicos a vitaminas, fortificantes, plantas medicinais e essênciais florais, elas estimulariam a automedicação por parte dos clientes.

Para a ANVISA, além de estimular os consumidores a comprar remédios de que não necessitam, as farmácias - amparadas por leis estaduais e municipais - vinham se transformando em verdadeiras lojas de conveniência, como as existentes em postos de gasolina, vendendo perfumes, brincos, barbeadores, lâminas, alimentos para dietas, chás, refrigerantes, sucos, energéticos, frutas, sorvetes e jornais.

\section{(...)}

(26) BARRETO, Sérgio Mena. A RDC 44 e normativas: o Brasil na contramão do mundo. São Paulo, 02 mar. 2010. Disponível em <http://www.febrafar.com.br/index.php?cat_id=8\&pag_id=6581 >. Acesso em: 24 mai. 2010. 
Com isso, a ANVISA colocou numa camisa de força um tipo de comércio varejista cujo funcionamento tem características próprias, que variam conforme o tamanho da cidade, a força econômica da região onde ela está situada e o perfil social de seus habitantes.

Além de prejudicar comerciantes e consumidores, a resolução da ANVISA os trata como pessoas desinformadas e incapazes de discernir o que estão adquirindo. Pelas novas regras, os medicamentos inclusive os vendidos sem receita médica - deverão ficar atrás dos balcões, fora do alcance dos clientes. Isso vai causar filas desnecessárias, limitar o poder de escolha dos consumidores e estimular a velha prática dos "diagnósticos e orientações" feitas por balconistas — também chamada de "empurroterapia".(27)

Corretas as críticas acima. Não se pode concordar com o argumento da Agência no sentido de que a população adquire medicamentos por puro impulso. Até porque são poucos aqueles que têm dinheiro sobrando para "gastar" ou consumir sem necessidade. Mas a liberdade que o cliente tinha de consultar os medicamentos que a própria Agência classificou como medicamentos de risco potencialmente baixo (isentos de prescrição, de venda livre) acabou. Assim, caberá ao próprio funcionário do estabelecimento pegar o medicamento.

Qual medicamento será que ele pegará? O mais caro ou o mais barato? O de alta ou de baixa rotatividade? O de marca (referência) ou o similar? Quais as garantias a mais que terá o consumidor por essa intermediação relacionada aos medicamentos isentos de prescrição?

É pura ilusão que, pelo simples fato do consumidor ter que solicitar o produto no balcão, haverá garantia da orientação farmacêutica. Primeiro, porque o quadro de funcionários do estabelecimento não é composto somente por farmacêuticos (aliás, em muitos casos, será privilégio do consumidor se houver algum responsável técnico presente, disponível para ser consultado).

Segundo, é da própria natureza econômica do estabelecimento a busca da melhor venda, a cobertura da oferta, a famosa frase do "leve dois, pague um". A prática da "empurroterapia" seria quase absoluta.

Imaginando pelo limite: o consumidor aparece com um pedido de compra enorme de analgésicos. Alguém acredita seriamente que o vendedor se recusará a fechar o negócio? Digamos que o balconista ainda pergunte: Mas por que o senhor quer tanta coisa? E o consumidor, mal-humorado, responda: Não é da sua conta.

Pode o vendedor negar a venda? Não pode. Não há lei que proíba uma pessoa de comprar 50 envelopes de analgésicos. O consumidor poderia até acusar o vendedor de discriminação.

(27) O EXCESSO de zelo da Anvisa. O Estado de S. Paulo, São Paulo, p. A3, 20 fev. 2010. 
Admitamos que o balconista consiga não fazer a venda. O que faz o consumidor? Vai a outras farmácias.

Mas o vendedor pode orientar o comprador, tal é a alegação. Pode?

Difícil. Esse funcionário do balcão não é farmacêutico. Pode ter experiência, mas raramente será um técnico treinado no assunto. Sim, ele pode chamar o farmacêutico que deveria estar ali 24 horas. Pode, talvez num estabelecimento pequeno, não certamente nas lojas maiores, dado o imenso movimento.

Além disso, sabe-se que muitas farmácias não cumprem a regra de ter sempre um farmacêutico por ali. Eis um ponto interessante: em vez de encontrar um meio de resolver esse problema, a ANVISA cria outras regras, que complicam a vida daquelas farmácias que já cumprem as atuais e mantêm o profissional de plantão. ${ }^{(28)}$

Qual é a efetiva medida do risco relacionado ao consumo de medicamentos isentos de prescrição?

Como se sabe, há muitas categorias de medicamentos. Assim, apenas com fins didáticos (ou seja, sem o compromisso de se nominar tecnicamente cada uma das categorias), vamos admitir apenas a existência de três grandes categorias: (i) medicamentos sujeitos a controle especial (de tarja preta). vendidos apenas com a retenção da receita ${ }^{(29)}$; (ii) medicamentos de venda sob prescrição médica (tarja vermelha); e (iii) medicamentos isentos de prescrição, de venda livre.

Desde o início, já se verifica um equívoco. A ANVISA não está levando em consideração que a automedicação é praticada pelo uso de medicamentos cuja apresentação da receita é necessária ou obrigatória, no caso dos medicamentos controlados. Então, seguindo pela lógica da Agência, admitamos apenas por ora que os "vilões" da intoxicação, da automedicação e do consumo irracional de medicamentos sejam apenas os medicamentos isentos de prescrição.

Ora, se os medicamentos isentos de prescrição já foram classificados como medicamentos com potencial de risco bem menor do que outros medicamentos, cujo consumo não causará maiores problemas, por que a retirada deles do alcance dos consumidores diminuirá os índices de intoxicação, de automedicação, do consumo irracional ou de reações adversas? Parece-nos, com todo o respeito, que se a preocupação é o "risco" pelo consumo desmedido, irracional e sem orientação desses medicamentos, a ANVISA deveria reclassificá-los para a categoria de medicamentos de venda sob prescrição médica.

(28) SARDENBERG, Carlos Alberto. Quem sabe comprar um comprimido? O Estado de S. Paulo, São Paulo, 22 fev. 2010, p. B2.

(29) A Portaria SMS/MS n. 344/98 aprova o Regulamento Técnico sobre substâncias e medicamentos sujeitos a controle especial vendidos apenas com apresentação e retenção de receita. 
Outra questão: todos os medicamentos isentos de prescrição causam intoxicação, automedicação, consumo irracional e provocam reações adversas?

Em caso positivo, por que alguns deles ainda podem ficar ao alcance dos consumidores? O risco desses medicamentos é menor do que os demais? O meio de administração (oral, por exemplo) causa menos risco ou provoca menos reações adversas do que a forma de pomada (uso tópico, dermatológico)? Os medicamentos fitoterápicos também não provocam reações indesejadas, se consumidos irracionalmente?

Por que todos os medicamentos isentos de prescrição não foram para trás do balcão? Qual a diferença existente entre os medicamentos isentos de prescrição que levou a Agência a abrir exceção e permitir a exposição na forma atual dos medicamentos fitoterápicos, de notificação simplificada e de uso dermatológico? O risco não é o mesmo? Ora, há ou não há risco a ser prevenido com a retirada dos medicamentos de venda livre das gôndolas?

À luz destas questões, parece-nos que o objetivo da ANVISA de beneficiar o consumidor, garantir a assistência e a orientação farmacêutica, evitar a automedicação e o uso irracional de medicamentos não se harmonizam com as mudanças trazidas pela RDC n. 44/2009. Se há riscos a serem prevenidos, todos os medicamentos isentos de prescrição deveriam ir para dentro do balcão. Ou então, a Agência deve reconsiderar os riscos relacionados a esses medicamentos, promovendo-os para a categoria de venda com prescrição médica.

Outro aspecto que chama a atenção é o destaque dado pela Agência no sentido de que os números e as estatísticas apresentadas pelo Sistema Nacional de Informações Tóxico-Farmacológicas (SINITOX) comprovam que os maiores agentes causadores de intoxicação em seres humanos são os medicamentos.

Infelizmente o estudo não diferencia quais as classes de medicamentos (controlados, de venda sob prescrição ou de venda livre) são os maiores causadores de intoxicação. Seria preciso qualificar, dentro do universo de medicamentos, quais deles seriam os maiores causadores da intoxicação humana.

Não nos parece apropriado dizer que as intoxicações são causadas (todas ou, pelo menos a maioria) por medicamentos isentos de prescrição, dado o próprio potencial de risco inferior oferecido por esses medicamentos.

No entanto, um estudo revela que "A livre compra de medicamentos, para cuja dispensação seria obrigatória a apresentação de receita médica $(44,1 \%)$, se por um lado demonstra o pouco caso ou desconhecimento em relação às normas regulamentares, por outro evidencia as dificuldades de acesso a uma atenção médica e farmacêutica adequadas." (30) (grifos nossos)

(30) ARRAIS, Paulo Sérgio D.; COELHO, Helena Lutéscia L.; BATISTA, Maria do Carmo D. S.; CARVALHO, Marisa L.; RIGHI, Roberto E.; ARNAU, Josep Maria. op. cit., p. 71-77. 
Ora, os medicamentos mais procurados segundo o estudo, são os medicamentos para cuja dispensação já seria obrigatória a apresentação de receita médica. Aparentemente, ao que nos parece, não são os medicamentos isentos de prescrição que são as maiores causas de intoxicação, mas sim os medicamentos de venda sob prescrição médica, exatamente aqueles que já estavam atrás do balcão!

Merece destaque: o não cumprimento da obrigatoriedade da apresentação da receita médica e a carência de informação são os principais problemas que levam à automedicação e à intoxicação. Ora, a automedicação é o efeito e a intoxicação é a consequência. Muito mais eficazes seriam as ações dos órgãos reguladores se elas estivessem direcionadas às causas do problema, não aos efeitos, nem tampouco às consequências!

O estudo ainda revela que a tendência dos países desenvolvidos é de aumento do número de medicamentos de venda livre - bem como a disponibilidade desses produtos em outros locais não farmacêuticos. No entanto,

nesses países, os rígidos controles estabelecidos pelas agências reguladoras e o crescente envolvimento dos farmacêuticos com a orientação dos usuários de medicamentos, tornam menos problemática a prática da automedicação. Já no Brasil, (...) a má qualidade da oferta de medicamentos, o não cumprimento da obrigatoriedade da receita médica e a carência de informação e instrução na população em geral justificam a preocupação com a qualidade da automedicação praticada no País. ${ }^{(31)}$ (grifos nossos)

E porque são vendidos medicamentos de venda sob prescrição médica sem a apresentação da respectiva prescrição? Simplesmente porque se eles não fizerem a venda, o consumidor atravessa a rua e o adquire em outra farmácia. Ou seja, não há fiscalização. Se os estabelecimentos fossem autuados e punidos de acordo com as leis já existentes por não observar essas regras - todos eles, - será que a dispensação desses medicamentos continuaria? Seguramente, não.

O estudo acima ainda concluiu que a população não está corretamente instruída com relação ao consumo dos medicamentos:

a escolha de medicamentos é baseada principalmente na recomendação de pessoas leigas (51,0\%), sendo também relevante a influência de prescrições anteriores (40,0\%). Com relação ao segundo aspecto, é possível que a última visita ao médico (36,0\% durante o período da pesquisa) tenha influenciado sobremaneira o perfil dos medicamentos escolhidos. ${ }^{(32)}$

(31) ARRAIS, Paulo Sérgio D.; COELHO, Helena Lutéscia L.; BATISTA, Maria do Carmo D. S.; CARVALHO, Marisa L.; RIGHI, Roberto E.; ARNAU, Josep Maria. op. cit., p. 72.

(32) Id. Ibid., p. 76. 
Essa conclusão do estudo é de fácil explicação: quantos desses pacientes tiveram acesso a médicos e hospitais?

Destarte, o problema a ser atacado - e que o Governo, os órgãos reguladores e demais instituições não conseguem resolver - é o problema do acesso aos serviços de saúde. Se a farmácia ou a drogaria é o primeiro estabelecimento que o cidadão procura quando se encontra em situação de agravo à sua saúde, contra esse problema é que os esforços devem se concentrar!

Mais uma vez, uma relação de causa e de efeito. A Agência agiu no efeito: a automedicação irresponsável e a intoxicação. Não considerou os motivos que levam a essa consequência. A falta de médicos é um problema grave que assola o País, que ainda possui diversos municípios sem nenhum hospital público e diversas cidades sem médico em nenhum dia do ano(33).

O CRF/SP é uma das entidades que mais apoia a RDC n. 44/2009. Em seu projeto "Farmácia estabelecimento de Saúde", expõe que (i) os Medicamentos Isentos de Prescrição oferecem baixo risco à saúde inclusive de abuso; (ii) a automedicação, se for feita em uma certa medida e com a necessária orientação, pode favorecer a recuperação da saúde:

Geralmente, os MIP são indicados para doenças com alta morbidade e baixa gravidade e são considerados de elevada segurança de uso, eficácia comprovada cientificamente ou de uso tradicional reconhecido, de fácil utilização e baixo risco de abuso, como, por exemplo, os antiácidos, os analgésicos e os antitérmicos. Os MIP podem ser vendidos, comprados, solicitados, fornecidos, dispensados

(33) Sobre essa questão, oportuno conferir matéria veiculada na Rede Globo de Televisão, no programa "Fantástico" exibida no último dia 16 de abril de 2010, disponível no site de notícias de Rede Globo de Televisão (www.g1.com): APESAR de novo código de ética, médicos continuam faltando. Disponível em: <http://fantastico.globo.com/Jornalismo/FANT/0, MUL1573182-15605,00APESAR+DE+NOVO+CODIGO+DE+ETICA+MEDICOS+CONTINUAM+FALTANDO.html> Acesso em: 10 jun. 2010. Nesse mesmo sentido, manifesta-se Sérgio Mena Barreto em seu blog disponível no site da ABRAFARMA, no comentário FALTAM médicos e por consequência receitas médicas <http:/ /www.abrafarma.com.br/blog.htm> Acesso em: 29 mai. 2010. "Matéria do Programa Fantástico da Rede Globo exibida no último domingo, dia 16/Abril, exibiu uma cena comum: a falta de médicos nos hospitais. Esse é o Brasil de verdade. Pesquisadores da Universidade Federal de Minas Gerais apontaram, em estudo recente, que a população de 455 municípios do Brasil não tem acesso a nenhum médico na rede pública de saúde EM NENHUM DIA DO ANO. Em cerca de 1.000 municípios há médico em média SOMENTE UMA VEZ POR MÊS. Pra deixar claro: 30\% dos municípios brasileiros têm grave problema de acesso a profissional médico, e por consequência, a tratamento e receitas de medicamentos. O problema não se resume à Região Norte, geralmente mais carente, onde o percentual de cidades que não possuem nenhum médico em sua estrutura de saúde chega a 25,7\%. Em 25,5\% dos municípios do Sul e 24,4\% do Sudeste também não há médicos. No PSF (Programa de Saúde da Família), 35\% dos municípios brasileiros continuam sem atendimento algum. Levanto esse tema em razão da recorrência em se colocar a culpa nas farmácias e drogarias pela venda de medicamentos sem receitas. Na verdade falta acesso. E é muito simplório, pra não dizer vexatório, alguém falar que esse é um problema do varejo, como vemos sempre por aí. É um problema de gestão pública. E de todos nós, sociedade brasileira." 
ou doados sem obrigatoriedade de nenhuma formalização de documento emitido por profissional legalmente habilitado para prescrevê-lo (OPAS, 2008). O seu uso tende a ser aceito hoje pelos órgãos sanitários como parte integrante do sistema de saúde. $\underline{O}$ fácil acesso aos MIP torna-os diretamente atrelados à automedicação, prática comum, devida (sic) à dificuldade de atendimento médico (demora na marcação de consultas médicas, atendimento precário em pronto-socorros, etc.). A automedicação, condenada por muitos, em alguns casos, se feita de forma correta, pode ser desejável. A Organização Mundial de Saúde (OMS) define a automedicação responsável como "prática dos indivíduos em tratar seus próprios sintomas e males menores com medicamentos aprovados e disponíveis sem a prescrição médica e que são seguros quando usados segundo as instruções" e a recomenda como forma de desonerar o sistema público de saúde. É válido ressaltar que o conceito da automedicação responsável não deve ser confundido com autoprescrição (uso sem receita médica de medicamentos tarjados). Em países como EUA, Canadá, Japão e países da União Europeia, a automedicação é prática consolidada, sendo a automedicação responsável utilizada principalmente para o tratamento de sintomas e doenças sem gravidade, como gripes, resfriados, dores de cabeças comuns, alguns tipos de micoses, dores musculares, entre outras enfermidades. ${ }^{(34)}$ (grifos nossos)

A passagem acima denota que o problema não é a automedicação, mas sim a falta de acesso à informação e ao tratamento médico, seguido pela orientação do farmacêutico. Se realizada com a supervisão e orientação de profissional habilitado, a automedicação é prática desejável e recomendada pelas organizações supranacionais, inclusive como forma de desonerar os serviços de saúde. Porém, a automedicação só ocorrerá de modo responsável e com a necessária orientação se o farmacêutico responsável técnico estiver presente no estabelecimento.

É o farmacêutico o profissional regularmente habilitado e capacitado para supervisionar o consumo racional de medicamentos. Aliás, no aspecto da assistência farmacêutica nesses estabelecimentos, o CRF/SP e a ANVISA estão cobertos de razão.

Em verdade, é justamente a necessidade da presença do farmacêutico responsável técnico nesses estabelecimentos durante todo o horário de funcionamento que os colocam na classificação de estabelecimentos comerciais de produtos de interesse da saúde. Não há a necessidade de responsável técnico em outros estabelecimentos comerciais. Mas, no comércio

(34) Disponível no site CONSELHO REGIONAL DE FARMÁCIA DO ESTADO DE SÃO PAULO. Fascículo II - Medicamentos isentos de prescrição. Disponível em: <http://www.crfsp.org.br/joomla/ index.php?option=com_docman\&task=cat_view\&gid=205\&ltemid=108>. Acesso em: 26 mai. 2010. 
farmacêutico, a presença dele é imprescindível. É o farmacêutico presente nos estabelecimentos que garantirá a exata medida de equilíbrio e harmonia entre o "consumismo", próprio do mundo capitalista - acentuado no mercado brasileiro - com as reais necessidades dos consumidores.

De fato, a presença do responsável técnico nos estabelecimentos farmacêuticos é uma das questões mais importantes para solucionar o problema do uso irracional de medicamentos, consumo inadequado e cuidados com interações medicamentosas. Porém, aqui se impõe destacar outro problema: o Brasil não possui profissionais farmacêuticos em número suficiente para atender a demanda.

Segundo informações do Conselho Federal de Farmácia ${ }^{(35)}$, há mais de 79.000 farmácias e drogarias registradas. Entretanto, os farmacêuticos inscritos nos Conselhos Regionais somam pouco mais de 133.000 profissionais. Sabe-se que nem todos esses profissionais trabalham em farmácias e drogarias, mas apenas para argumentar, levemos em consideração somente os dados relacionados às farmácias e drogarias existentes no País. Admitindo que todos esses profissionais fossem absorvidos pelas farmácias e drogarias, fica evidente a insuficiência na assistência farmacêutica. Um estabelecimento comum que funcione apenas em horário comercial precisaria, no mínimo, de dois farmacêuticos. Daí por que, embora a lei exija a presença de técnico responsável, a maioria dos estabelecimentos não conta com a necessária assistência, o que torna impossível cumpri-la.

Silva e Vieira (2004) publicaram um estudo com o propósito de caracterizar o perfil dos responsáveis técnicos nas drogarias e avaliar o conhecimento sobre alguns aspectos da legislação que rege o funcionamento de drogarias e da profissão. Os dados são preocupantes: de acordo com a metodologia do estudo, o nível de conhecimento a respeito da legislação sanitária foi considerado insuficiente para $28 \%$ dos profissionais; regular para $50 \%$; e bom apenas para $22 \%{ }^{(36)}$.

Mais preocupante ainda, o estudo revelou carência de conhecimento no próprio exercício da profissão. Por exemplo, quase metade dos farmacêuticos entrevistados (46\%) afirmaram que "(...) o medicamento Dorflex® (um relaxante muscular que contém uma associação de orfenadrina, dipirona e cafeína) é de venda livre, ou seja, 46\% desconhecem a exigência de prescrição médica para esse medicamento."(37) De acordo com o estudo

(35) Cf. no site do CONSELHO FEDERAL DE FARMÁCIA. Estatísticas, estabelecimentos farmacêuticos no Brasil. Disponível em: <http://www.cff.org.br/\#[ajax]pagina\&id=138>. Acesso em: 26 maio 2010 e CONSELHO FEDERAL DE FARMÁCIA. Relação de profissionais inscritos. Disponível em: <http:// www.cff.org.br/\#[ajax]pagina\&id=139>. Acesso em: 26 mai. 2010.

(36) SILVA, Luci Rodrigues da; VIEIRA, Elisabeth Meloni. Conhecimento dos farmacêuticos sobre legislação sanitária e regulamentação da profissão. Revista de Saúde Pública, São Paulo, v. 38, n. 3, p. 429-437, 2004.

(37) Id. Ibid., p. 429. 
(...) as faculdades de farmácia provavelmente não fornecem subsídios teóricos básicos e práticos para que os futuros farmacêuticos possam atuar na dispensação de medicamentos.

Os farmacêuticos que trabalham nas drogarias não têm sua formação voltada para a prática da atenção farmacêutica, sendo em sua maioria habilitados para a indústria e as análises clínicas. Fica constatada a necessidade de formação do farmacêutico centrada no conhecimento dos medicamentos, inclusive da legislação sanitária, para que no futuro possam exercer plenamente a profissão, sem ameaças penais ou prejuízos à população. Os treinamentos e reciclagens (em serviço) na área de dispensação de medicamentos, acompanhados pela supervisão direta e educação continuada, deveriam também integrar as propostas de ações das entidades de classe e associações da categoria, com a efetiva participação do aparelho formador. (grifamos)

Por isso, antes de se pensar na automedicação responsável e no consumo racional de medicamentos, é preciso capacitar os profissionais que dirigem tecnicamente os estabelecimentos para que eles tenham condições de assumir essa grave responsabilidade.

Se nem mesmo os farmacêuticos sabem que é necessário ter um responsável técnico presente durante todo o horário de funcionamento do estabelecimento, se são incapazes de apontar as diferenças entre um medicamento genérico de um similar, ou um medicamento de venda livre para outro de venda sob prescrição, como é que eles poderiam assumir a responsabilidade de "estabelecimentos de saúde"? Não há como atribuir a eles a responsabilidade para dirigir esses estabelecimentos, sem antes pensar na capacitação desses profissionais.

Por outro lado, preocupa-nos bastante a proposta do Conselho Federal de Farmácia no sentido de propor uma normatização para a regulamentação das "atribuições e competências do farmacêutico na prescrição farmacêutica"(38). Mesmo não estando preparados sequer para assumir responsabilidades técnicas e desenvolver atividades elementares enquanto técnicos farmacêuticos das drogarias e farmácias, o Conselho Federal de Farmácia quer aprovar uma Resolução que dê ao farmacêutico da drogaria a atribuição de prescrever medicamentos isentos de prescrição. Essa medida é realmente absurda.

A prescrição é um ato privativo do médico, assim como é privativo do farmacêutico a dispensação de medicamentos sujeitos a controle especial.

(38) Cf. a Consulta Pública n. 01/2010, disponível no site do CONSELHO FEDERAL DE FARMÁCIA. Consultas Públicas. Disponível em: <http://www.cff.org.br/\#[ajax]noticia\&id=407>. Acesso em: 26 mai. 2010. 
Não é a classificação do medicamento que atribui a este ou aquele profissional a realização de determinado procedimento. Em se tratando de prescrição de medicamentos (qualquer medicamento que seja) estamos diante de uma capacitação técnico-profissional, da formação em curso superior em medicina e da obtenção de um diploma. Ainda que a grade curricular dos cursos de medicina e farmácia sejam parcialmente convergentes e se pareçam em determinados momentos - o que a propósito é salutar - não é por isso que o farmacêutico pode praticar atos privativos dos médicos!

Com uma crítica bastante dura contra a proposta do Conselho Federal de Farmácia, Carlos Alberto Sardenberg assim se manifestou:

(...) Mas o Conselho Federal de Farmácia (...) prepara uma resolução determinando que todos os medicamentos isentos de prescrição médica só poderão ser vendidos com uma prescrição farmacêutica.

(...) Haverá, portanto, uma espécie de consulta obrigatória, com o farmacêutico, para a compra de qualquer medicamento, por mais simples que seja, e isso tudo seria determinado por uma resolução do Conselho Federal de Farmácia. A ANVISA apoia essa proposta do conselho, pois é uma maneira de contrabandear e ampliar aquela outra resolução [a RDC n. 44/2009]. Pela norma da ANVISA, o consumidor vai precisar fazer uma ficha e obter a receita do farmacêutico, mesmo para um medicamento que ele mesmo, consumidor, escolheu e que normalmente usa. Difícil imaginar outro meio de torrar a paciência dos consumidores. Difícil também imaginar outro meio de tumultuar e encarecer um comércio que funciona relativamente bem. $O$ argumento da ANVISA e do conselho sustenta que as regras destinam a evitar 0 uso indevido de medicamentos isentos de prescrição e, assim, prevenir reações adversas e/ou interações medicamentosas. Mas esse tipo de problema não é, propriamente, uma calamidade nacional, nem sequer uma preocupação grave. Não há notícia de que a coisa no Brasil esteja fora de controle. O que ocorre mais é problema com o uso indevido de medicamentos, digamos, mais perigosos, justamente aqueles que precisam de prescrição - e que são vendidos sem a receita. Tem a venda no contrabando que vem do Paraguai, por exemplo, que é um assunto da polícia. Mas muitas farmácias legalmente estabelecidas também vendem sem prescrição e depois compram receitas de médicos. Ora, em vez de tratar desse assunto, a ANVISA e o Conselho de Farmácia querem introduzir outra prescrição e outra ficha. O argumento de que o brasileiro não sabe comprar remédio não se justifica. Os números não indicam uso excessivo dos medicamentos livres, mesmo porque as pessoas não estão com dinheiro sobrando para comprar um remédio novo só para experimentar a novidade. (...) o Conselho está obviamente preocupado em garantir mais postos de trabalho para os farmacêuticos. Resultado: se isso tudo vingar, vão conseguir duas 
coisas: aumentar o preço dos remédios e tirar a liberdade de o cidadão comprar um simples comprimido para dor de cabeça. ${ }^{(39)}$

A proposta atribui ao farmacêutico uma responsabilidade para cujo exercício ele não foi capacitado. Além do que, como já dissemos acima, se o problema que se quer evitar é o risco pela intoxicação por medicamentos isentos de prescrição, a ANVISA deveria propor uma reclassificação para os isentos de prescrição, de modo que os fármacos que, em tese, oferecem mais riscos, sejam vendidos mediante a apresentação de receita médica. Além disso, os medicamentos que causam maior intoxicação na população não são os medicamentos isentos de prescrição, mas sim aqueles que para serem vendidos, já é exigida a receita médica. Portanto, não seria o caso de se intensificar a fiscalização, punindo os infratores de acordo com a lei? Por óbvio que sim.

Ademais, a proposta do Conselho Federal de Farmácia para implementar a prescrição de medicamentos pelo farmacêutico é um verdadeiro absurdo. Nem mesmo suas atribuições elementares, típicas da função como responsável técnico de drogaria ou de farmácia, o farmacêutico domina, conforme demonstrou o estudo de Silva e Vieira (2004). Imaginemos, pois, as consequências desastrosas dessa proposta. Como bem afirmou José Ruben de Alcântara Bonfim, da Sociedade Brasileira de Vigilância de Medicamentos (Sobravime), nem sempre é fácil definir o que é um "transtorno menor". "É preciso experiência e algumas habilidades que se aprendem na faculdade de Medicina." Já o vice-presidente do Conselho Federal de Medicina (CFM), Carlos Vital, afirma que a legislação brasileira prevê que o diagnóstico e a prescrição são atos que pertencem ao âmbito médico ${ }^{(40)}$.

\section{O COMÉRCIO DE PRODUTOS ALHEIOS AO RAMO FARMACÊUTICO}

Além da questão dos medicamentos isentos de prescrição, a ANVISA também proibiu o comércio de outros produtos, classificados pelas autoridades como produtos estranhos à atividade. A ampliação do mix de produtos comercializados nas farmácias e drogarias desvirtua esses estabelecimentos de suas funções, que devem ser comprometidas com a recuperação da saúde. Segundo o $\mathrm{CRF/SP}$.

(39) SARDENBERG, Carlos Alberto. O brasileiro sabe cuidar de sua vida? O Estado de S. Paulo, São Paulo, SP, p. B2, 07 jun. 2010.

(40) PROJETO prevê que farmacêutico prescreva analgésicos e antiácidos. O Estado de São Paulo, São Paulo, SP, 22 Jun. 2010. Disponível em: <http://www.estadao.com.br/noticias/geral,projetopreve-que-farmaceutico-prescreva-analgesicos-e-antiacidos, 570349,0.htm\#bb-md-noticia-tabs-1>. Acesso em: 22 jun. 2010. 
Quanto maior a quantidade de outros produtos comercializados, menor o tempo gasto com o acompanhamento farmacoterapêutico, a atenção farmacêutica e a farmacovigilância. O usuário por desconhecimento da legislação nem sempre exige a assistência farmacêutica no momento da dispensação, ou será que ele se distrai com as outras mil opções de compra encontradas? A definição dos produtos cuja venda é permitida em farmácias e drogarias atende os anseios de toda a classe farmacêutica, uma vez que existem divergências até entre os órgãos de fiscalização. ${ }^{(41)}$

A questão aqui a ser analisada é o alcance do conceito de produto correlato. De acordo com o art. 4ㅜ, inciso IV da Lei n. 5.991/73, correlato é:

a substância, produto, aparelho ou acessório não enquadrado nos conceitos anteriores, cujo uso ou aplicação esteja ligado à defesa e proteção da saúde individual ou coletiva, à higiene pessoal ou de ambientes, ou a fins diagnósticos e analíticos, os cosméticos e perfumes, e, ainda, os produtos dietéticos, óticos, de acústica médica, odontológicos e veterinários.

Além disso, a lei permite o comércio de outros produtos, típicos de lojas de conveniência. A Lei n. 9.069/1995 acrescentou no art. 4ํ da Lei n. 5.991/73 o inciso $X X$ que traz o conceito de loja de conveniência e drugstore: "estabelecimento que, mediante auto-serviço ou não, comercializa diversas mercadorias, com ênfase para aquelas de primeira necessidade, dentre as quais alimentos em geral, produtos de higiene e limpeza e apetrechos domésticos, podendo funcionar em qualquer período do dia e da noite, inclusive nos domingos e feriados."

O comércio de outros produtos não tira o foco da natureza desses estabelecimentos, até porque a própria lei permite o comércio de produtos de "primeira necessidade". É até plausível admitir que o consumidor vá à farmácia para comprar um medicamento qualquer e acabe levando um chocolate ou um suco. Mas não se pode admitir o contrário: ninguém vai à farmácia para comprar um chocolate e acaba levando um comprimido por mero acaso. E isso não ocorre pela própria natureza desses estabelecimentos.

A concorrência que abre um leque de ofertas desapareceria, dando lugar ao monopólio de algumas marcas e acarretando preços mais altos que os atuais. Essa decisão é um caminho inverso do de mercados desenvolvidos, em que a farmácia tem incluído não medicamentos com uma série de facilidades para o consumidor. Vale lembrar também que a norma da ANVISA está na contramão do que pensa a população. Para os brasileiros, é clara a diferença entre medicamentos e não medicamentos. ${ }^{(42)}$

(41) Disponível no site do CONSELHO REGIONAL DE FARMÁCIA DO ESTADO DE SÃO PAULO. Fascículo I - Projeto. Disponível em: <http://www.crfsp.org.br/joomla/Diversos/ PDFFciaEstSaude.pdf>. Acesso em: 30 mai. 2010.

(42) BARRETO, Sérgio Mena. Medicamento nunca foi bem de consumo. Folha de S. Paulo, São Paulo, 20 fev. 2010. Disponível em <http://www.abrafarma.com.br/artigo_01.htm>. Acesso em: 26 
A ABRAFARMA propôs uma ação coletiva em face do CRF/SP com vistas a obter medida para assegurar a expedição do Certificado de Regularidade independentemente do fato de seus associados comercializarem produtos alheios ao ramo farmacêutico. Não é objeto deste trabalho analisar o mérito daquela ação, porém, um trecho da sentença proferida em 31 de maio de 2010 merece destaque:

(...) Deixo, ainda, registrado que o estabelecimento farmacêutico deve ser visto como estabelecimento comercial, que atende, dentro do possível, as necessidades da população. Não acredito que o fato deste estabelecimento comercializar medicamentos e correlatos deve impedir a população de ter acesso a outros produtos alheios ao ramo farmacêutico - claro, desde que não haja a constituição de outro estabelecimento totalmente díspare dentro da farmácia ou drogaria - sob a alegação de atender ao interesse público. Ora, o interesse público é o interesse de todos, o bem comum sempre buscado com a atuação da Administração, onde estaria este bem comum com a proibição em questão? O que se tem de evitar e proteger o indivíduo é no que se refere à automedicação, em que o Brasil é campeão mundial, mas isto se faz não com a proibição de comercialização nestes estabelecimentos de outros produtos, mas sim com fiscalização adequada.

Outrossim, alegações de que a comercialização de produtos alheios aos do ramo farmacêutico implicaria em contaminação destes últimos, devido a presença de insetos no armazenamento, dentre outros argumentos, é causa para a adequada e intensa fiscalização, e não para o impedimento do exercício da livre iniciativa. Ademais, insetos podem haver até mesmo em se tratando de farmácias e drogarias que nada comercializem além de produtos farmacêuticos, bastando encontrarem-se em lugar propício a tanto, o que não é difícil encontrarse. E ainda, se fossemos impedir a comercialização de produtos sob este argumento, simplesmente os supermercados não existiriam. ${ }^{(4)}$ (grifos nossos)

Além de inoportuna e imprestável ao objetivo almejado, a proibição de comercialização de outros produtos nas farmácias e drogarias esbarra em leis estaduais e municipais que permitem expressamente o comércio desses produtos. No Estado de São Paulo, a Lei n. 12.623/2007 permite às farmácias e drogarias o comércio de diversos produtos tipicamente questionados por

mai. 2010. É oportuno destacar que, em pesquisa realizada pelo IBOPE em novembro de $2009,73 \%$ dos entrevistados afirmaram ser contra a proibição de venda de produtos de conveniência e serviços nas farmácias. O levantamento ouviu 1.302 pessoas de seis capitais. A margem de erro foi de $3 \%$.

(43) Juíza Federal Substituta da 14ª Vara Cível da Justiça Federal da Seção Judiciária de São Paulo Cláudia Rinaldi Fernandes (Processo n. 2007.61.00.031844-5). 
autoridades, como sendo produtos estranhos à atividade farmacêutica. $O$ então Governador José Serra havia vetado a Lei, porém, os deputados paulistas derrubaram o veto. O Governo propôs então uma Ação Direta de Inconstitucionalidade, que ainda se encontra em tramitação no Supremo Tribunal Federal. Romano-Lieber (2008)(44) diz que:

Lei Estadual n. 12.623/07 contrapõe-se ao conjunto de Leis Federais, cuja evolução vem buscando trazer conotação mais precisa ao significado restrito de estabelecimento de saúde às farmácias e drogarias, em consonância com as recomendações supranacionais que o país procura atender. A Ação Direta de Inconstitucionalidade, em face da Lei Estadual n. 12.623/07, orienta-se no fato de que, na sua concepção, existe contrariedade com a competência da União em legislar sobre as normas gerais da proteção e defesa da saúde. A lei extrapola os limites determinados pela Lei Federal que disciplina a matéria ao estabelecer a venda de produtos de conveniência em farmácias e drogarias. Em resumo, como salientado na própria Ação, o legislador estadual, ao disciplinar o comércio de artigos de conveniência em farmácias e drogarias, não se restringiu àqueles produtos que se enquadrassem na modalidade de correlatos, conforme a Lei n. 5.991/ 73, diretamente ligados à defesa e proteção da saúde individual ou coletiva, mas entendeu como lícita a comercialização de todo e qualquer artigo de conveniência, contemplando inúmeros itens que nada têm a ver com a saúde pública.

Em que pese tais ponderações, a improcedência dos argumentos é manifesta. O Advogado-Geral da União manifestou-se nos autos daquela Ação Direta de Inconstitucionalidade e, com argumentos robustos, rebate:

(...) a presente controvérsia limita-se a aferir a (in)constitucionalidade da Lei n.12623/07, do Estado de São Paulo, em face do art. 24, XII da Constituição da República, cuja inteligência, em síntese, determina competir à União, no âmbito da competência legislativa concorrente entre ela, os Estados e o Distrito Federal, ditar normas gerais sobre proteção e defesa da saúde.

Tal disposição encontra-se intimamente ligada àquela constante do art. 196 da mesma Carta Política, que determina ser a saúde direito de todos e dever do Estado, este, no caso, compreendido pelos entes integrantes da Federação, especialmente União, Estados e Distrito Federal, responsáveis pela alocação de grande parte dos recursos destinados à saúde.

A propósito, essa confluência de competências levada a efeito pelo caput e pelos incisos do referido art. 24 encontra-se certo grau de

(44) ROMANO-LIEBER, Nicolina Silva; CUNHA, Marcelo Ferreira Carlos; RIBEIRO, Eliane, op. cit., p. 188-199. 
distribuição interna nos parágrafos subsequentes. O primeiro deles limita a competências da União ao estabelecimento de normas gerais, ou seja, normas principiológicas, de interesse geral; o segundo e o terceiro cuidam da competência suplementar (complementar e suplementar propriamente dita) dos Estados e do Distrito Federal, isso é, diante das normas gerais fixadas pela União, podem complementálas, orientados pelas circunstâncias de interesse local. (...)

Aplicando esse raciocínio ao caso sub judice, evidencia-se que a Lei $n$. 12623/07, do Estado de São Paulo, foi editada em perfeita consonância com o disposto no $\S 2^{\circ}$ do art. 24 da Constituição de 1988, porquanto cuidou de questões de interesse regional, sem afastar a observância à norma geral quanto ao tema, já editada pela União (Lei n. 5991/73, que traça normas gerais sobre 'o controle sanitário do comércio de drogas, medicamentos, insumos farmacêuticos e correlatos)'.

Assim, ao contrário do que afirmado pelo Requerente, a lei estadual impugnada impõe-se, expressamente, às farmácias e drogarias instaladas no estado, o dever de 'cumprir todas as normas técnicas e preceitos legais específicos à comercialização de cada produto', dentro as quais se inclui o diploma federal supramencionado.

A Ação ainda não foi julgada em definitivo, mas espera-se que o Supremo Tribunal Federal julgue a ação improcedente, reconhecendo-se que a lei observa os princípios constitucionais e em nada prejudica o comércio farmacêutico. E na medida em que a lei seja considerada constitucional, seguramente não será nociva à saúde. Pelo contrário, contribuirá para a economia, para a livre iniciativa e se coadunará com os interesses da população revelados na pesquisa feita pelo IBOPE em novembro/2009.

\section{CONSIDERAÇÕES FINAIS}

Por todos os aspectos acima expostos, parece-nos que a ANVISA não acertou ao interferir em um comércio que já funcionava com relativa eficiência. A medida que propôs a retirada dos medicamentos isentos de prescrição do alcance dos consumidores não trará os resultados almejados pelas autoridades.

Primeiro, porque a simples retirada não evitará que os produtos sejam adquiridos livremente. Além do mais, não são esses produtos que provocam as intoxicações, as reações adversas e o uso irracional de medicamentos. Os medicamentos que mais provocam intoxicação são aqueles para os quais a dispensação já exige apresentação de receita médica. Pior ainda, pois em alguns estabelecimentos, o consumidor tem acesso até mesmo a medicamentos controlados - para cuja dispensação é necessária a retenção da receita médica. 
Se a culpa do problema da intoxicação realmente fosse dos medicamentos isentos de prescrição, ou seja, se de fato esses medicamentos expusessem o consumidor a um risco de relevância pública, eles deveriam ser reclassificados como medicamentos de venda sob prescrição. Com essa medida, de modo muito mais técnico e rigoroso, os medicamentos seriam dispensados aos consumidores, inclusive porque a propaganda - uma das ferramentas mais efetivas dos fabricantes relacionadas aos medicamentos de venda sob prescrição - obedece a requisitos ainda mais rigorosos.

Assim, se os medicamentos que mais causam intoxicação não são os isentos de prescrição, a retirada deles do alcance do consumidor será para esta finalidade, inócua. Por outro lado, transferirá para o funcionário do estabelecimento a decisão da venda. Além do mais, como vimos, ao oferecer o medicamento de venda livre, isento de prescrição, o funcionário sempre buscará a melhor venda, o que implicará em aumento do custo dos medicamentos e diminuição da concorrência em prejuízo do consumidor.

Antes de se propor medida como essa, os órgãos reguladores deveriam identificar os motivos pelos quais os consumidores vão às drogarias e farmácias para comprar medicamentos por conta própria. Não é opção da população, que não tem acesso aos serviços públicos de saúde. Nos hospitais e postos de saúde, é raro encontrar um médico disponível. E se há médico, ele não dá conta de atender à imensa demanda.

A dificuldade em se agendar consultas, a falta de profissionais (e de especialistas) são problemas muito mais importantes e muito mais complexos que geram consequências no mercado farmacêutico. Se o paciente não consegue agendar consulta, consequentemente, não terá prescrição. Não tendo prescrição, mas sentindo dor, ele se automedica.

A automedicação é um efeito, ou uma consequência de um problema. Ora, se não há médicos, não há prescrições; não havendo prescrições, não há (ou haveria) consumo de medicamentos. Mas, como vimos, há consumo. Então, se mesmo sem prescrições médicas, há consumo de medicamentos (a ponto de ele ser o maior agente causador de intoxicação no Brasil), é certo que não há fiscalização.

A fiscalização não é da responsabilidade dos estabelecimentos farmacêuticos, assim como não é da farmácia a responsabilidade pela intoxicação por medicamentos. A automedicação e o uso irracional são efeitos decorrentes de uma política de saúde ineficiente e incapaz de atender à demanda da população. No modelo universalista de saúde pública adotado pela Constituição Federal, o Governo e as autoridades ainda têm muito que fazer antes de propor medidas como essa, de retirar do alcance dos consumidores os medicamentos isentos de prescrição sob o argumento de que os medicamentos causam intoxicação e a automedicação deve ser evitada. 
Além do mais, as novas regras para o comércio farmacêutico se revelam insuficientes para enfrentar o problema da automedicação e do uso irracional de medicamentos. Pior do que insuficiente, será a futura constatação de que essas medidas contribuíram para o agravamento da situação. Isto porque, como vimos, será o recrudescimento definitivo da "empurroterapia".

Se couber aos funcionários do estabelecimento a "indicação" de medicamentos, por motivos óbvios, os consumidores acabarão sendo "convencidos" de que o medicamento deve ser adquirido. O consumo não será só certo, mas será mais caro, na medida em que o funcionário sempre procurará a melhor venda, em detrimento da concorrência entre os fabricantes. Ficando sob a responsabilidade do farmacêutico da drogaria ou farmácia a indicação do medicamento, seguramente o paciente pagará mais caro por um produto que tinha um concorrente de menor preço.

E mais: terá sorte o consumidor que encontrar um farmacêutico presente. Mais sorte ainda, se esse farmacêutico tiver conhecimentos considerados "mínimos" para o exercício da profissão. As universidades não estão preparando e capacitando os profissionais de modo adequado. O ensino superior do curso de farmácia precisa urgentemente de uma reformulação, para que esses profissionais possam exercer plenamente suas tarefas na drogaria.

Despejados no mercado de trabalho, boa parte desses farmacêuticos mostra-se incapaz de assumir responsabilidades elementares, inerentes do exercício de sua função como diretor técnico do estabelecimento. Daí por que eles não podem assumir uma "nova" responsabilidade de prescrever medicamentos isentos. A prescrição de medicamentos é ato privativo do médico e o exercício dessa atribuição pressupõe conhecimentos que não fazem parte da grade curricular do ensino de farmácia.

Atribuir ao farmacêutico a responsabilidade de prescrever medicamentos, de realizar alguns serviços tipicamente feitos por médicos, ou seja, transformar um estabelecimento comercial em um estabelecimento de saúde será desastroso. Como demonstrado acima, poucos são os farmacêuticos que estão capacitados para assumir tamanha responsabilidade. A maioria desses profissionais sequer sabe diferenciar um medicamento de referência do genérico. Pouquíssimos dominam suas atribuições na farmácia e na drogaria e pouquíssimos conhecem a legislação sanitária que regula suas atividades.

Antes de se pensar em atribuir tamanha responsabilidade a eles, seria necessário melhorar a qualidade do ensino nas faculdades, aprimorar a qualificação e capacitação desses profissionais para exercerem suas funções nesses estabelecimentos. Além do mais, é preciso incentivar a formação de novos profissionais, pois as faculdades não conseguem formar tantos profissionais quanto se faz necessário para atendimento da demanda. 
Por fim, é inerente da sociedade capitalista o conflito existente entre a saúde-direito e a saúde-mercadoria. Sem nenhuma dúvida, a solução deste conflito não está na simples edição de regulamentos e normas jurídicas. Pelo contrário, a tensão se expressa nesses regulamentos, expondo ainda mais suas fragilidades.

Essa tensão fica bastante clara em se tratando do comércio de produtos de conveniência e primeira necessidade nos estabelecimentos farmacêuticos. Conforme exposto, a presença desses produtos não trará nenhum prejuízo à população e à saúde pública, nem tampouco contaminará o ambiente com vetores nocivos à saúde. Mesmo porque a exposição desses produtos nas lojas observa a separação física e totalmente desvinculada do ambiente destinado aos medicamentos, sendo, portanto, um procedimento economicamente viável, sem qualquer implicação nociva à saúde.

Por óbvio, aqui não se defende que os estabelecimentos transformem-se em verdadeiros mercados, açougues, lojas de material escolar ou de construção. Porém, observadas as leis esparsas existentes nas várias esferas de Governo, o comércio de produtos de conveniência é possível e não traz prejuízo algum.

Destarte, é possível que a retirada dos medicamentos isentos de prescrição traga algum resultado no sentido de diminuir o consumo. Mas, seguramente, a medida se revela absolutamente ineficiente e ineficaz contra o propósito para o qual ela foi instituída. A automedicação, infelizmente, continuará se o Governo não agir nas causas do problema. Há muito ainda a se fazer ANTES da retirada dos medicamentos isentos de prescrição do alcance do paciente.

\section{REFERÊNCIAS BIBLIOGRÁFICAS}

ABRAMSON, J. "The commercial takeover of medical knowledge" e "The snake and the staff". In: Overdo\$ed America. Harper Collins: New York, 2004. p. 93-128.

AITH, Fernando Mussa Abujamra. Teoria geral do direito sanitário. 2006. Tese (Doutorado em Saúde Pública) - Faculdade de Saúde Pública da Universidade de São Paulo, São Paulo, 2006. Disponível em <http:// www.teses.usp.br/teses/disponiveis/6/6135/tde-23102006-144712/publico/ TeseFernandoAith.pdf>. Acesso em: 26 maio 2010.

ANGELL, M. Buying influence. In: The truth about the Drug Companies. Random House: New York, 2004. p. 173-216.

The FDA - regulation and reaction, Patent games - stretching out monopolies. In: The truth about the Drug Companies. Random House: New York, 2004. p. 31-36. 
ANGONESI, Daniela. Dispensação farmacêutica: uma análise de diferentes conceitos e modelos. Revista Ciência \& Saúde Coletiva, São Paulo, v. 13, (sup.), p. 629-640, 2008.

ANVISA. Anvisa anuncia novas regras para farmácias e drogarias. 18 ago. 2009. Disponível em: <http://www.anvisa.gov.br/divulga/noticias/2009/ 180809_2.htm>. Acesso em: 24 mai. 2010

. Consulta Pública n. 69, de 11 de julho de 2007. Proposta de resolução que dispõe sobre o Regulamento Técnico de Boas Práticas Farmacêuticas em Farmácias e Drogarias. Diário Oficial da União, Brasília, DF, 13 Jul. 2007, Seção 1. Disponível em <http://www4.anvisa.gov.br/base/visadoc/CP/ CP[19073-1-0].PDF>. Acesso em: 10 mai. 2010.

Consumo e saúde, farmácia: local de promoção à saúde. Disponível em: <http://www.anvisa.gov.br/ouvidoria/consumo_saude/11_090909.pdf>. Acesso em: 29 maio 2010.

. Disponível em: <http://bvsms.saude.gov.br/bvs/saudelegis/anvisa/ 2006/res0199_26_10_2006_rep.html>. Acesso em: 29 mai. 2010.

Disponível em: <www.anvisa.gov.br>.

Instrução Normativa - IN n. 10, de 17 de agosto de 2009. Aprova a relação de medicamentos isentos de prescrição que poderão permanecer ao alcance dos usuários para obtenção por meio de auto-serviço em farmácias e drogarias. Diário Oficial da União, Brasília, DF, 18 Ago. 2009. Seção 1, p. 83.

Instrução Normativa - IN n. 9, de 17 de agosto de 2009. Dispõe sobre a relação de produtos permitidos para dispensarão e comercialização em farmácias e drogarias. Diário Oficial da União, Brasília, DF, 18 Ago. 2009. Seção 1, p. 82-83.

Medicamentos (Medicamentos Fitoterápicos). Disponível em: <http:// www.anvisa.gov.br/medicamentos/fitoterapicos/definicao.htm>. Acesso em: 29 mai. 2010.

. Resolução da Diretoria Colegiada - RDC n. 44, de 17 de agosto de 2009. Dispõe sobre Boas Práticas Farmacêuticas para o controle sanitário do funcionamento, da dispensação e da comercialização de produtos e da prestação de serviços farmacêuticos em farmácias e drogarias e dá outras providências. Diário Oficial da União, Brasília, DF, 18 Ago. 2009. Seção 1, p. 78-81.

Uso racional de medicamentos é assunto de painel em Brasília. 11 fev. 2010. Disponível em: <http://portal.anvisa.gov.br/wps/portal/anvisa/busca/ !ut/p/c5/04_SB8K8xLLM9MSSzPy8xBz9CP0os3hnd0cPE3MfAwMDMydn A093Uz8z00B_AwN_Q_1wkA48Kowg8gY4gKOBvp9Hfm6qfkF2dpqjo6liA $\mathrm{JYj}$ 8M!/dl3/d3/L2dJQSEVUUt3QS9ZQnZ3LzZfS1FISUcwMDI5T1Q4RDBJN FRSSDILQ09GMTE!/?WCM_GLOBAL_CONTEXT=/wps/wcm/connect/Anvisa/ Anvisa/Sala+de+Imprensa/Noticias/Uso+racional+de+medicamentos+e+ assunto+de+painel+em+Brasilia>. Acesso em: 29 mai. 2010. 
APESAR de novo código de ética, médicos continuam faltando. Disponível em: <http://fantastico.globo.com/Jornalismo/FANT/0,,MUL1573182-15605,00APESAR+DE+NOVO+CODIGO+DE+ETICA+MEDICOS+CONTINUAM+FALTANDO. html>. Acesso em: 10 jun. 2010.

ARRAIS, Paulo Sérgio D.; COELHO, Helena Lutéscia L.; BATISTA, Maria do Carmo D. S.; CARVALHO, Marisa L.; RIGHI, Roberto E.; ARNAU, Josep Maria. Perfil da automedicação no Brasil. Revista de Saúde Pública, São Paulo, v. 31, n. 1, 71-77, 1997.

ASSOCIAÇÃO MÉDICA DO PARANÁ. É drogaria ou supermercado? Disponível em: <http://amp.org.br/?p=2354>. Acesso em: 28 mai. 2010.

AUDIÊNCIA PÚBLICA - COMISSÃO DE ASSUNTOS SOCIAIS DO SENADO, 6 Maio 2009. Brasília, DF. Disponível em <http://www.senado.gov.br/sf/ comissoes/cas/ap/ano-de-2009/AP20090506_Apresenta\%C3\%A7\%C3\%A30 ANVISA.pdf>. Acesso em: 24 mai. 2010.

AUTOMEDICAÇÃO: Responsabilidade de quem? Revista Ascoferj. Rio de Janeiro, Maio 2010. Disponível em <http://www.sindifarmajp.com.br/ noticias.php?not_id=2332>. Acesso em: 24 mai. 2020.

BARRETO, Sérgio Mena. Medicamento nunca foi bem de consumo. Folha de S. Paulo, São Paulo, 20 fev. 2010. Disponível em <http://www.abrafarma.com.br/ artigo_01.htm>. Acesso em: 26 mai. 2010.

A RDC 44 e normativas: o Brasil na contramão do mundo. São Paulo, 02 Mar. 2010. Disponível em <http://www.febrafar.com.br/index.php? cat_id=8\&pag_id=6581 >. Acesso em: 24 mai. 2010.

BRASIL. Constituição (1988). Constituição da República Federativa do Brasil, promulgada em 5 de outubro de 1988. 40. ed. at. e ampl. São Paulo: Saraiva, 2007.

Decreto n. 74.170, de 10 de junho de 1974. Regulamenta a Lei $n$. 5.991, de 17 de dezembro de 1973, que dispõe sobre o controle sanitário do comércio de drogas, medicamentos, insumos farmacêuticos e correlatos. Diário Oficial da União, Brasília, DF, 11 Jun. 1974. Seção 1. Disponível em <http://www.planalto.gov.br/ccivil_03/decreto/Antigos/D74170.htm>. Acesso em: 10 mai. 2010.

. Lei n. 5.991, de 17 de dezembro de 1973. Dispõe sobre o Controle Sanitário do Comércio de Drogas, Medicamentos, Insumos Farmacêuticos e Correlatos, e dá outras providências. Diário Oficial da União, Brasília, DF, 19 Dez. 1973. Seção 1. Disponível em<http://www.planalto.gov.br/ccivil_03/Leis/ L5991.htm>. Acesso em: 10 mai. 2010.

Lei n. 9.069, de 29 de junho de 1995. Dispõe sobre o Plano Real, o Sistema Monetário Nacional, estabelece as regras e condições de emissão do Real e os critérios para conversão das obrigações para o Real, e dá 
outras providências. Diário Oficial da União, Brasília, DF, 30 Jun. 1995. Seção 1. Disponível em <http://www.planalto.gov.br/ccivil_03/Leis/L9069.htm\#art74>. Acesso em: 10 mai. 2010.

Ministério da Saúde. Fundação Oswaldo Cruz. Sistema Nacional de Informações Tóxico-Farmacológicas - SINITOX. Brasília, DF. Disponível em <http://www.fiocruz.br/sinitox_novo/cgi/cgilua.exe/sys/start.htm?tpl=home>. Acesso em: 24 mai. 2010.

Ministério da Saúde. Manual de direito sanitário com enfoque na vigilância em saúde. Brasília, DF, 2006.

Resolução da Secretaria de Estado de Saúde do Estado do Paraná n. 54, de 03 de junho de 1996 - Norma técnica que regula a abertura e o funcionamento de estabelecimentos farmacêuticos. Disponível em: <http:// www.saude.pr.gov.br/arquivos/File/Legislacao/estudual_resolucao/ 96RPR54.pdf>. Acesso em: 10 jun. 2010.

CARRETAS, Valter. Sobre a RDC n. 44/2009 da ANVISA. Curitiba, PR. 19 Ago. 2009. Disponível em <http://www.advocaciavaltercarretas.com.br/ index.php?option=com_content\&view=article\&id=150:sobre-a-rdc-442009da-anvisa\&catid=20:artigos\&ltemid=84>. Acesso em: 24 mai. 2010.

CONSELHO FEDERAL DE FARMÁCIA. Consultas Públicas. Disponível em: <http://www.cff.org.br/\#[ajax]noticia\&id=407>. Acesso em: 26 mai. 2010

. Estatísticas, estabelecimentos farmacêuticos no Brasil. Disponível em: <http://www.cff.org.br/\#[ajax]pagina\&id=138>. Acesso em: 26 mai. 2010.

Relação de profissionais inscritos. Disponível em: <http:// www.cff.org.br/\#[ajax]pagina\&id=139>. Acesso em: 26 mai. 2010.

CONSELHO REGIONAL DE FARMÁCIA DO ESTADO DE SÃO PAULO. Fascículo I - Projeto. Disponível em: <http://www.crfsp.org.br/joomla/ Diversos/PDFFciaEstSaude.pdf>. Acesso em: 30 mai. 2010.

. Fascículo II - Medicamentos isentos de prescrição. Disponível em: <http://www.crfsp.org.br/joomla/index.php?option=com_docman\&task= cat_view\&gid=205\&ltemid=108>. Acesso em: 26 mai. 2010.

Projeto Farmácia Estabelecimento de Saúde. Fascículo I, São Paulo, 2009. Disponível em <http://www.crfsp.org.br/joomla/index.php?option=com _docman\&task=doc_download\&gid=149\&ltemid=108>. Acesso em: 26 maio 2010.

Projeto Farmácia Estabelecimento de Saúde. Fascículo II Medicamentos isentos de prescrição, São Paulo, 2009. Disponível em <http:// www.crfsp.org.br/joomla/index.php?option=com_docman\&task=doc_ download\&gid=150\&ltemid=108>. Acesso em: 26 mai. 2010. 
. Projeto Farmácia Estabelecimento de Saúde. Fascículo III - Serviços farmacêuticos, São Paulo, 2009. Disponível em <http://www.crfsp.org.br/ joomla/index.php?option=com_docman\&task=doc_download\&gid=154\& Itemid=108>. Acesso em: 26 mai. 2010.

CUNHA, Marcelo Ferreira Carlos. A racionalidade da mercantilização da doença. Dissertação (Mestrado em Saúde Pública) - Faculdade de Saúde Pública da Universidade de São Paulo. 2008. Disponível em <http:// www.teses.usp.br/teses/disponiveis/6/6135/tde-24102008-160756/publico/ MarceloCunha.pdf>. Acesso em: 14 abr. 2010.

ESTABELECIMENTO de saúde. Disponível em: <http://www.crfsp.org.br/ joomla/Diversos/PDFFciaEstSaude.pdf>.

FALTAM médicos e por conseqüência receitas médicas. Disponível em: <http:// www.abrafarma.com.br/blog.htm>. Acesso em: 29 mai. 2010.

GUIA DA FARMÁCIA. Disponível em: <www.guiadafarmacia.com.br>. <http:// guiadafarmacia.com.br/gestao-merchandising/201/debate-lista-reduzidaanvisa-propoe-que-produtos-considerados-conveniencia-deixem-1675691.asp>. Acesso em: 24 mai. 2010.

HARVEY, D. Neo-liberalism as creative destruction. The annals of the American Academy of Political and Social Science, v. 610, n. 21, p. 22-44, 2007.

MELLO, Dirceu Raposo de. Saúde é direito, e não simples mercadoria. Folha de S. Paulo, São Paulo, 20 fev. 2010. Disponível em: <http:// www.interfarma.org.br/site2/index.php/artigos-e-noticias/artigos/32-saude-edireito-e-nao-simples-mercadoria>. Acesso em: 26 mai. 2010.

O EXCESSO de zelo da Anvisa. O Estado de S. Paulo, São Paulo, p. A3, 20 fev. 2010.

PAULO, L.G.; ZANINE A.C. Automedicação no Brasil. Rev. Ass .Med. Bras., v. 34, p. 69-75, 1988.

PROJETO prevê que farmacêutico prescreva analgésicos e antiácidos. $O$ Estado de São Paulo, São Paulo, SP, 22 Jun. 2010. Disponível em: <http:// www.estadao.com.br/noticias/geral, projeto-preve-que-farmaceuticoprescreva-analgesicos-e-antiacidos,570349,0.htm\#bb-md-noticia-tabs-1>. Acesso em: 22 jun. 2010.

ROMANO-LIEBER, Nicolina Silva; CUNHA, Marcelo Ferreira Carlos; RIBEIRO, Eliane. A farmácia como estabelecimento de saúde. Revista de Direito Sanitário, São Paulo, v. 9, n. 3, p. 188-199, 2008.

SÃO PAULO (Estado). Lei n. 12.623, de 25 de junho de 2007. Disciplina o comércio de artigos de conveniência em farmácias e drogarias, de modo a proporcionar segurança e higiene ao consumidor. Diário Oficial do Estado, São Paulo, SP, 26 Jun. 2007. Disponível em <http://www.legislacao.sp.gov.br/ dg280202.nsf/ae9f9e0701e533aa032572e6006cf5fd/9c2bc534c3ffe39b032 573070053dffd?OpenDocument>. Acesso em: 22 jun. 2010. 
SARDENBERG, Carlos Alberto. O brasileiro sabe cuidar de sua vida? $O$ Estado de S. Paulo, São Paulo, SP, p. B2, 07 jun. 2010.

Quem sabe comprar um comprimido? O Estado de S. Paulo, São Paulo, p. B2, 22 fev. 2010.

A vida tem preço e é cara. O Estado de São Paulo, São Paulo, 01 Mar. 2010. Disponível em <http://www.interfarma.org.br/site2/index.php/ artigos-e-noticias/artigos/288-a-vida-tem-preco-e-e-cara>. Acesso em: 26 mai. 2010.

SENADO. Audiência Pública da Comissão de Assuntos Sociais do Senado de 06 de maio de 2009. Boas práticas farmacêuticas em farmácias e drogarias. Disponível em: <HTTP://senado.gov.br/web/comissoes/cas/ap/ano-de-2009/ ap20090506_apresenta\%C3\%A7\%C3\%A3oANVISA.pdf>. Acesso em: 29 mai. 2010.

SILVA, Gustavo Henrique Trindade da.; OLIVEIRA, Neilton Araújo de. Farmácia e drogaria: simples comércio ou estabelecimento de saúde? Biblioteca Virtual em Saúde. Blog Direito Sanitário: Saúde e Cidadania, 05 Mar. 2010. Disponível em <http://blogs.bvsalud.org/ds/2010/03/05/farmaciae-drogaria-simples-comercio-ou-estabelecimento-de-saude/>. Acesso em: 24 mai. 2010.

SILVA, Luci Rodrigues da. Conhecimentos e atitudes dos farmacêuticos sobre a regulamentação da profissão e funcionamento de drogarias - uma abordagem sanitária. Dissertação (Mestrado em Saúde Pública) — Faculdade de Medicina de Ribeirão Preto, Universidade de São Paulo, 2002. Disponível em: <http://www.ribeiraopreto.sp.gov.br/ssaude/principal/acervo/pdf/i16tesesms.pdf>. Acesso em: 26 mai. 2010.

; VIEIRA, Elisabeth Meloni. Conhecimento dos farmacêuticos sobre legislação sanitária e regulamentação da profissão. Revista de Saúde Pública, São Paulo, v. 38, n. 3, p. 429-437, 2004.

SILVER, Lynn. Consumidores, profissionais, Governo e comércio debatem a farmácia como estabelecimento de saúde. Revista Riopharma. Rio de Janeiro, mar./abr. 2002. Disponível em: <http://www.crfrj.org.br/crf/revista/47/ 4_47.asp>. Acesso em: 24 mai. 2010.

UNIVERSIDADE PRESBITERIANA MACKENZIE. 4. ed. Apresentação de trabalhos acadêmicos: guia para alunos da Universidade Presbiteriana Mackenzie. São Paulo, 2006.

WORLD HEALTH ORGANIZATION. INTERNATIONAL PHARMACEUTICAL FEDERATION. Developing pharmacy practice: a focus on patient care, handbook 2006. Netherlands: World Health Organization/International Pharmaceutical Federation. 2006. 97 p. Disponível em <http://www.fip.org/ files/fip/publications/DevelopingPharmacyPractice/DevelopingPharmacy PracticeEN.pdf>. Acesso em: 26 jun. 2010. 